\title{
Quantifying the contribution of a subpopulation to inequality an application to Mozambique
}

\section{Carlos Gradín ${ }^{1}$}

Received: 31 May 2018 / Accepted: 24 January 2020/Published online: 14 July 2020

(C) UNU-WIDER 2020

\begin{abstract}
In this paper, I quantify the contribution of a subpopulation to inequality. This is defined as the sum of the contributions of its members, with these contributions computed as the impact on inequality of a small increase in the population mass at each point of the distribution (using the Recentered Influence Function). The decomposition is shown to verify various attractive properties. I also discuss alternative approaches used in the literature of factor inequality decompositions. I show that the RIF and the marginal and Shapley factor contributions are approximately equal in the case of the Mean Log Deviation, the index with the best additive decomposability properties, when the same normalization is used. In an empirical illustration, I use the approach to identify how the richest, highly educated, and urban population has disproportionally contributed to high and increasing inequality in Mozambique in recent years.
\end{abstract}

Keywords Inequality $\cdot$ Decomposition $\cdot$ RIF $\cdot$ Shapley $\cdot$ Marginal $\cdot$ Mozambique

JEL Classification D31 $\cdot$ D63 $\cdot$ O15

\section{Introduction}

The analysis of inequality by subpopulations has long been a key element for a better understanding of inequality levels and trends across countries. The aggregate decomposition of inequality between and within subpopulations obtained from various geographical and socioeconomic characteristics is a simple and powerful tool that helps us to identify the sources of inequality and its dynamics in different societies. The literature has already developed a sound analytical framework. Shorrocks (1984, 1988) has restricted the class of measures that are subgroup consistent, for which overall inequality increases with inequality in any group, ceteris paribus. This class is defined by the family of Generalized Entropy indices and any monotonic transformation, which includes the Atkinson

Carlos Gradín

gradin@wider.unu.edu

1 United Nations University - World Institute for Development Economics Research (UNU-WIDER), Helsinki, Finland 
family but not the popular Gini index. Scalar transformations of the Generalized Entropy family, alone, define a more specific class, the set of additively decomposable measures, in which inequality is the sum of inequality between groups and the weighted sum of inequality within groups (Shorrocks 1980). Two members of this class proposed by Theil (1967) - the Mean Log Deviation and the Theil index - have become the most popular in empirical analysis of decompositions for their straight interpretation of the within-group component because the weights are respectively given by population and income shares. The Mean Log Deviation can be singled out as the only one whose decomposition does not depend on the path followed to break total inequality into its two components. Nevertheless, the decomposability properties of other indices have also been explored and used in empirical analyses. This is true of the role of overlapping among subpopulations in the Gini index (e.g. Bhattacharya and Mahalanobis 1967; Rao 1969) and the multiplicative decomposability of the Atkinson family of (equality) indices (e.g. Blackorby et al. 1981). These aggregate decompositions, however, do not allow to explicitly identify the role of specific groups.

This paper contributes to this classical literature by proposing a simple framework into which we can go a step further and provide a more detailed decomposition by identifying the contribution of each subpopulation to overall inequality using the most popular indices. ${ }^{1}$ In the case of additively decomposable indices, one can also identify the contribution to each component (between-group and within-group), mimicking the aggregate decomposition.

Following an individualistic approach, I define the contribution of a group to inequality as the sum of the contributions of its members, obtained by assessing the impact that a marginal increase in the proportion of people with a specific income would have on total inequality using the statistical notion of the Recentered Influence Function (RIF). This is not the only reasonable approach, though. For that reason, I also explore alternative approaches adapted from the factor inequality decomposition literature. I argue that contributions based on the natural decomposition rule of some indices are not especially attractive in this context. Then, I focus on the marginal contribution of a group, along an extension based on the Shapley decomposition that averages over all possible sequences in which groups are considered. For the especial case of the Mean Log Deviation- the index with the best additive decomposability properties - I show that the RIF, marginal and Shapley approaches are almost equivalent assuming a normalization property that is reasonable in the context of additively decomposable indices, i.e. a group with all incomes equal to the population mean has a null contribution to overall inequality. The three approaches may differ, though, for other indices of the same class.

The contributions obtained with all three approaches will generally verify the usual properties of the target inequality indices (such as replication or scale invariance, or higher sensitivity to certain parts of the distribution). In this context, however, the linear RIF approach provides higher consistency in the decomposition because group contributions add up to total inequality and are independent of the level of disaggregation of groups. Furthermore, the RIF decomposition is straightforward to compute (including the standard errors).

The RIF contribution of a group can be obtained from the coefficients of group membership dummies in RIF regressions. Thus, the detailed RIF decomposition by subpopulations provides the researcher with a tool that is strongly complementary with one of the two main approaches used in the literature of regression-based inequality decompositions proposed in

\footnotetext{
${ }^{1}$ Although I focus here on inequality, the same approach can be used to explain the contribution of groups to other distributional statistics such as poverty, mobility, polarization, etc.
} 
Firpo et al. (2007, 2009). ${ }^{2}$ As Cowell and Fiorio (2011) have already noted, the two branches of the literature evolved highly disconnected one to each other.

I illustrate the potential of this approach with an analysis of the role of subpopulations defined by different household characteristics to explain the level and trend of consumption inequality in Mozambique, a low-income sub-Saharan African country that has shown a significant increase in inequality in recent years. The results will show the disproportional contributions to inequality and its increase over time of top percentiles, urban areasespecially the capital Maputo - and of households with heads having higher education.

The next section describes the proposed RIF decomposition, while the third section discusses other possible approaches. The fourth section introduces the data and an application to explain inequality in Mozambique in the 2008/09-2014/15 period. The last section concludes with final remarks.

\section{The RIF decomposition of inequality by subpopulations}

\subsection{The total contribution of a subpopulation to inequality}

Let us consider an exhaustive partition of a population into $K \geq 1$ disjoint groups, with superscript $k$ referring to the $k$ th group. Each group has a distribution $\boldsymbol{y}^{\boldsymbol{k}}=\left(y_{1}^{k}, . ., y_{n^{k}}^{k}\right)$, with population size $n^{k}$ and mean income $\mu^{k}$. The population of $n=\sum_{k=1}^{K} n^{k}$ individuals is represented by $\boldsymbol{y}=\left(\boldsymbol{y}^{\mathbf{1}}, \ldots, \boldsymbol{y}^{\boldsymbol{K}}\right)$ with mean income $\mu$.

The Influence Function of an inequality index $I F(x ; I(y))$ measures the impact on inequality of marginally increasing the population mass at a certain income $x$ (i.e. a small contamination) and has an expected value of zero. More formally, if $\boldsymbol{y}_{\varepsilon}$ is a mixture distribution assigning a probability $1-\varepsilon$ to the original distribution $y$ and $\varepsilon$ to $x$ (see Hampel 1974):

$$
I F(x ; I(\boldsymbol{y}))=\left.\frac{\partial}{\partial \varepsilon} I\left(\boldsymbol{y}_{\varepsilon}\right)\right|_{\varepsilon=0} ; \text { with } E(I F(x ; I(\boldsymbol{y}))=0 .
$$

The Recentered Influence Function $R I F(x ; I(y))$ is obtained after recentering the IF (and its expected value) at the value of the target statistic (Firpo et al. 2007):

$$
R I F(x ; \mathrm{I}(\boldsymbol{y}))=I(y)+I F(x ; \mathrm{I}(y)) ; \text { with }(R I F(x ; I(y))=I(y) .
$$

The IF and RIF of several inequality measures have already been explored (Monti 1991; Schechtman 1991; Cowell and Flachaire 2002, 2007; Essama-Nssah and Lambert 2012). The corresponding expressions for discrete distributions for Gini and the Generalized Entropy family are shown in Table 1.

Let the contribution of the $j$ th individual of group $k$ to overall inequality $I(y)$, labelled as $S_{j}^{k}$, be the corresponding value of the per capita RIF estimated at $\mathrm{y}_{j}^{k^{3}}$ :

\footnotetext{
${ }^{2}$ These techniques allow to identify the contribution of several factors at the same time and/or to disentangle the compositional and structural effects in distributional changes. The other main approach is based on the factor decomposition of inequality using log-income regressions instead (Fields, 2003 and subsequent literature).

${ }^{3}$ Cowell and Victoria-Feser (1996) have previously used the IF to study the robustness of various inequality indices to measurement error.
} 


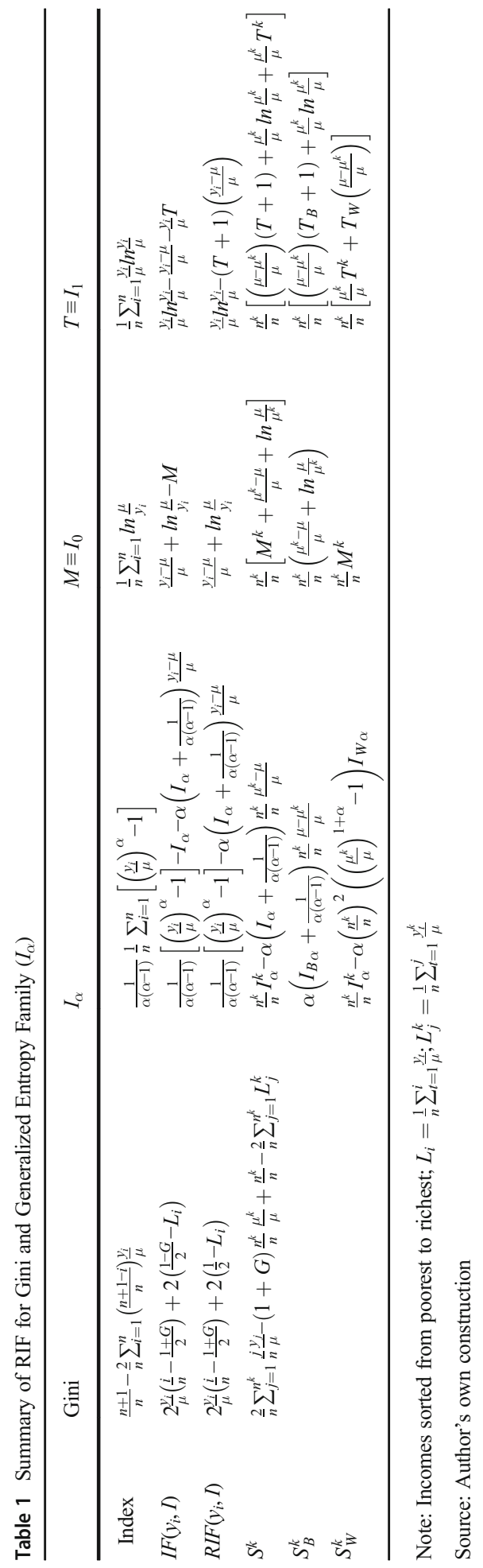




$$
S_{j}^{k} \equiv S_{j}^{k}(I(\boldsymbol{y}))=\frac{1}{n} R I F\left(y_{j}^{k} ; I(\boldsymbol{y})\right) .
$$

The contribution of group $k$, labelled as $S^{k}$, is defined to be the sum of the contributions of its members:

$$
S^{k} \equiv S^{k}(I(\boldsymbol{y}))=\sum_{j=1}^{n^{k}} S_{j}^{k}
$$

The relationship of $S^{k}$ with the RIF regressions is straightforward, when group membership dummies ( $\lambda^{k}=1$ if an individual belongs to group $k$; 0 otherwise) are used as explanatory variables:

$$
R I F\left(y_{j}^{k} ; I(\boldsymbol{y})\right)=\sum_{k=1}^{K} \widehat{\beta}^{k} \lambda^{k} ; \text { where } \widehat{\beta}^{k} \equiv \bar{S}^{k}=\frac{1}{n^{k}} \sum_{j=1}^{n^{k}} \operatorname{RIF}\left(y_{j}^{k} ; I(\boldsymbol{y})\right) .
$$

The corresponding estimated coefficient of the RIF regression indicates the average RIF of the members of the group, $\bar{S}^{k}$, and the RIF group contribution can be obtained by multiplying this value by the group population share, after aggregating for all members:

$$
S^{k}=\frac{n^{k}}{n} \widehat{\beta}^{k}
$$

In this context, in line with the RIF generalization of the Blinder (1973)-Oaxaca (1973) approach, a change in inequality could be decomposed into a compositional effect (i.e. changes in population sizes) and a structural effect (i.e. changes on the average RIF) ${ }^{4}$ :

$$
\Delta I(\boldsymbol{y})=\sum_{k=1}^{K} \Delta S^{k}=\sum_{k=1}^{K} \Delta\left(n_{k} / n\right) \bar{S}^{k}+\sum_{k=1}^{K}\left(n^{k} / n\right) \Delta \bar{S}^{k},
$$

where $\Delta$ stands for the change in any statistic between the two distributions. This decomposition is obtained after just adding and subtracting a counterfactual distribution with the initial group sizes (characteristics) and the final average RIF (coefficients):

$$
I^{c}(\boldsymbol{y})=\sum_{k=1}^{K} \frac{n^{k}}{n}\left(\bar{S}^{k}+\Delta \bar{S}^{k}\right) .
$$

It is interesting to note that the RIF approach applied to other simpler statistics provides very intuitive contributions. For example, the group size is the RIF contribution for the population size. The group mean and head-count ratio multiplied by the population share are the contributions for the corresponding population statistics (where $z$ is a given poverty threshold) ${ }^{5}$ :

$$
\begin{gathered}
S^{k}(n)=n^{k} ; \\
S^{k}(\mu)=\frac{n^{k}}{n} \mu^{k} ; \\
S^{k}(H(\boldsymbol{y} ; z))=\frac{n^{k}}{n} H\left(\boldsymbol{y}^{k} ; z\right) .
\end{gathered}
$$

\footnotetext{
${ }^{4}$ The most popular case has been the decomposition of the difference in quantiles (known as unconditional quantile decomposition (Firpo et al. 2007, 2009), but the approach has also been applied to aggregate inequality measures like Gini (e.g. Gradín, 2016 and referenced literature) and others (e.g. Gradín, 2018).

${ }^{5}$ Given that $\operatorname{RIF}\left(y_{i} ; n\right)=1, \operatorname{RIF}\left(y_{i} ; \mu\right)=y_{i}$, and $\operatorname{RIF}\left(y_{i} ; H\left(y_{i}, z\right)\right)=1$ if $y_{i}<z$ (=0 otherwise).
} 
The RIF contributions will inherit the properties of the corresponding inequality indices. For example, they will be invariant to replications of the entire population (population principle):

$$
S^{k}(I(\boldsymbol{y}))=S^{k}\left(I\left(\boldsymbol{y}^{\prime}\right)\right) \text { for any replication } \boldsymbol{y}^{\prime}=(\boldsymbol{y}, \ldots, \boldsymbol{y}) .
$$

They will also be invariant to the multiplication of all incomes in the population by the same factor (scale invariance):

$$
S^{k}(I(\boldsymbol{y}))=S^{k}(I(\lambda \boldsymbol{y})) \text { for any } \lambda>0 .
$$

The RIF of inequality indices generally show a U-pattern with respect to income (e.g. Gradín 2018). As a result, the contribution of a group to inequality will tend to be higher, ceteris paribus, the more people of this group have extreme incomes. The U-pattern will be asymmetric, though, reflecting the specific degree of sensitivity to income transfers that occur at different points of the distribution. The empirical section compares the cases of Gini, Theil and Mean Log Deviation indices for Mozambique.

Furthermore, the RIF decomposition verifies some important decomposability properties. Due to its linearity, the decomposition is consistent, overall inequality can be written as just the sum of all individual or group contributions:

$$
I(\boldsymbol{y})=\sum_{k=1}^{K} S^{k}=\sum_{k=1}^{K} \sum_{j=1}^{n^{k}} S_{j}^{k} .
$$

Therefore, one might be interested in estimating the proportion of total inequality explained by each group, i.e. the relative total contribution:

$$
s^{k}=S^{k} / I(\boldsymbol{y}) .
$$

Consistency also applies to further exhaustive partitions of group $k$, e.g. the contribution of a region in a country will be the sum of the contributions of the provinces integrating that region if they are computed separately.

Additionally, $S^{k}$ also verifies path independence with respect to the order in which the groups are considered and is invariant to the level of aggregation of other groups: the contribution of a group does not depend on how the other groups were clustered. For example, the contribution of a region does not change if the other regions are pooled together or considered as separate entities. Given the large variety of decomposability approaches, the next section investigates other decomposability features in the most common approach, additive decomposability.

The normalization and range of $S^{k}$ are index-specific. For example, the Generalized Entropy family explored in more detail in the next section, verifies an intuitive normalization property, according to which $S^{k}=0$ for a group with all incomes equal to the population mean $\left(y_{j}^{k}=\mu, \forall j=1, \ldots, n^{k}\right)$, while $S^{1}=I(y)$ if there is only one group in the population $(K=1)$. One special member of this family, the Mean Log Deviation-unlike other indices - also verifies an intuitive range property: $S^{k}$ will always fall between 0 and $I(\boldsymbol{y})$.

\subsection{The case of additively decomposable indices}

An inequality index is additively decomposable (e.g. Shorrocks 1984) if it can be written as the weighted sum of the inequality values calculated for the subpopulations (within-group 
inequality $I_{W}$ ) plus the contribution arising from differences between subpopulation means (between-group inequality $I_{B}$ ):

$$
I(\boldsymbol{y})=I_{B}+I_{W} .
$$

Let $\mathbf{1}_{s}$ be a row vector of $s$ ones and $\boldsymbol{\mu}^{\boldsymbol{k}}=\left(\mu^{1} \mathbf{1}_{n^{1}}, \ldots, \mu^{K} \mathbf{1}_{n^{K}}\right)$ the vector in which individual incomes $y_{j}^{k}$ are replaced by their corresponding group means $\mu^{k}$. Then, inequality within groups is defined as the level of inequality that goes away after equalizing incomes within groups, shifting from vector $\boldsymbol{y}$ to $\boldsymbol{\mu}^{k}$ :

$$
I_{W}=I(\boldsymbol{y})-I\left(\boldsymbol{\mu}^{\boldsymbol{k}}\right)=\sum_{k=1}^{K} I\left(\boldsymbol{y}^{\boldsymbol{k}}\right) w_{I}^{k},
$$

with $w_{I}^{k}$ being index-specific weights that might be a function of group population shares $n^{k / n}$ and relative incomes $\mu^{k / \mu}$.

Inequality between groups is the remaining level of inequality with $\boldsymbol{\mu}^{k}$ :

$$
I_{B}=I\left(\boldsymbol{\mu}^{k}\right) \text {. }
$$

The class of inequality indices that are additively decomposable and verify two basic properties, scale invariance and population replication, belongs (up to a scalar transformation) to the Generalized Entropy family $I_{\alpha}(\boldsymbol{y})$, including its limit when $\alpha=0,1$ (Shorrocks 1984). If subscript $i$ identifies the $i$ th individual of vector $y$ :

$$
I_{\alpha}(\boldsymbol{y})=\frac{1}{\alpha(\alpha-1)}\left[\frac{1}{n} \sum_{i=1}^{n}\left(\frac{y_{i}}{\mu}\right)^{\alpha}-1\right] ; \text { with } w_{I_{\alpha}}^{k}=\frac{n^{k}}{n}\left(\frac{\mu^{k}}{\mu}\right)^{\alpha} .
$$

The most popular indices of this class are the two limit cases obtained for $\alpha=0,1$ : The Mean Log Deviation $(M)$ and Theil $(T)$ indices, also previously characterized by Bourguignon (1979) and Foster (1983):

$$
\begin{aligned}
& M \equiv I_{0}=\frac{1}{n} \sum_{i=1}^{n} \ln \frac{\mu}{y_{i}} ; w_{M}^{k}=\frac{n^{k}}{n} . \\
& T \equiv I_{1}=\frac{1}{n} \sum_{i=1}^{n} \frac{y_{i}}{\mu} l n \frac{y_{i}}{\mu} ; w_{T}^{k}=\frac{n^{k}}{n} \frac{\mu^{k}}{\mu} .
\end{aligned}
$$

These are the two only cases in which the weights $w_{I_{\alpha}}^{k}$ used to construct the within-group component, respectively population and income shares, add up to 1 . In other cases, the sum of weights depends on the between-group term, making the interpretation more difficult.

Among these two indices, $M$ is known to be more sensitive to income transfers that occur in the lower tail of the distribution and has better decomposability properties. The decomposition of $M$ is more genuine because the within-group component does not depend on group mean incomes. As a result, only the additive decomposition of $M$ is independent of the path followed to define the two components (e.g. Chakravarty 2009; Foster and Shneyerov 2000). ${ }^{6}$

The contributions to total inequality are given by:

\footnotetext{
${ }^{6}$ As an alternative to the case mentioned above, inequality between groups could be defined first, as the level of inequality that goes away when incomes are rescaled in each group so as to eliminate mean differences across groups. Within-group inequality would be then the remaining level when there is no inequality between groups. This would not affect the aggregate decomposition of $M$, neither the groups contribution to each component defined below.
} 


$$
\begin{gathered}
S^{k}\left(I_{\alpha}\right)=\frac{n^{k}}{n}\left[I_{\alpha}^{k}-\alpha\left(I_{\alpha}+\frac{1}{\alpha(\alpha-1)}\right) \frac{\mu^{k}-\mu}{\mu}\right] ; \alpha \neq 0,1 . \\
S^{k}(M)=\frac{n^{k}}{n}\left[M^{k}+\frac{\mu^{k}-\mu}{\mu}+\ln \frac{\mu}{\mu^{k}}\right] . \\
S^{k}(T)=\frac{n^{k}}{n}\left[\left(\frac{\mu-\mu^{k}}{\mu}\right)(T+1)+\frac{\mu^{k}}{\mu} \ln \frac{\mu^{k}}{\mu}+\frac{\mu^{k}}{\mu} T^{k}\right] .
\end{gathered}
$$

In parallel to the aggregate decomposition above, we can consistently define the contribution of each group to the within-group term as the contribution to inequality that goes away after equalizing incomes within groups. The contribution to inequality between groups is the remaining contribution, based on the aggregate impact on between-group inequality of marginally increasing the population with $\mu^{k}$ :

$$
\begin{gathered}
S_{W}^{k}=S^{k}(I(\boldsymbol{y}))-S^{k}\left(I\left(\boldsymbol{\mu}^{k}\right)\right) . \\
S_{B}^{k}=S^{k}\left(I\left(\boldsymbol{\mu}^{k}\right)\right)=\frac{n_{k}}{n} R I F\left(\mu^{k} ; I\left(\boldsymbol{\mu}^{k}\right)\right) . \\
\text { with } S^{k}=S_{B}^{k}+S_{W}^{k} ; \\
\text { and } I_{B}=\sum_{k=1}^{K} S_{B}^{k} \text { and } I_{W}=\sum_{k=1}^{K} S_{W}^{k} .
\end{gathered}
$$

In the two cases of interest, it is straightforward to obtain the corresponding expressions (summarized in Table 1). The between-group component:

$$
\begin{gathered}
S_{B}^{k}(M)=\frac{n^{k}}{n}\left(\frac{\mu^{k}-\mu}{\mu}+\ln \frac{\mu}{\mu^{k}}\right) ; \\
S_{B}^{k}(T)=\frac{n^{k}}{n}\left[\left(\frac{\mu-\mu^{k}}{\mu}\right)\left(T_{B}+1\right)+\frac{\mu^{k}}{\mu} \ln \frac{\mu^{k}}{\mu}\right] .
\end{gathered}
$$

The between-group component in both indices is the sum of two terms: the direct contribution to the indices, which is the function of the relative mean that goes into the summation in $I_{B}$ (respectively $\frac{n^{k}}{n} \ln \frac{\mu}{\mu^{k}}$ and $\frac{n^{k}}{n} \frac{\mu^{k}}{\mu} \ln \frac{\mu^{k}}{\mu}$ ), and the indirect contribution capturing the impact of each group in the population mean (and thus in the relative means of the other groups).

The between-group term $S_{B}^{k}$ will be zero for $M$ and $T$ whenever $\mu^{k}=\mu$, and will monotonically increase the farther $\mu^{k}$ deviates from the critical value at which it reaches its minimum ( $\mu$ in the case of $M, \mu e^{T_{B}}>\mu$ in the case of $T$ ). For a given relative mean income, the contribution of a group to this term will rise with the population size in both cases. Thus, the indices verify mean income and population share monotonicity properties. It is noticeable that $S_{B}^{k}(M)$, unlike $S_{B}^{k}(T)$, is independent of the overall between-group inequality level. 
The corresponding within-group terms are given by:

$$
\begin{gathered}
S_{W}^{k}(M)=\frac{n^{k}}{n} M\left(\boldsymbol{y}^{\boldsymbol{k}}\right) . \\
S_{W}^{k}(T)=\frac{n^{k}}{n}\left[\frac{\mu^{k}}{\mu} T\left(\boldsymbol{y}^{k}\right)+T_{W}\left(\frac{\mu^{-} \mu^{k}}{\mu}\right)\right] .
\end{gathered}
$$

The within-group term $S_{W}^{k}(M)$ is just the weighted level of group inequality. $S_{W}^{k}(T)$, however, is the weighted level of group inequality $w_{T}^{k} T^{k}$ plus another term. This second term captures the indirect effect that a higher population mass at $\mu^{k}$ has on the total within-group term, given that the weights depend on $\mu^{k}$. Thus, $S_{W}^{k}(T)$, like $S_{W}^{k}(M)$, will monotonically increase with group size and inequality. But it will also be increasing with its relative mean if the group has higher inequality than the weighted average, $T\left(y^{k}\right)>T_{W}$, or decreasing otherwise. ${ }^{7}$ This is an unattractive property of the index decomposition related with its path dependence on the order in which $T_{W}$ and $T_{B}$ are defined. In particular, this implies that $T\left(\boldsymbol{y}^{k}\right)=0$ is not enough condition for $S_{W}^{k}(T)=0$, because group $k$ still influences the within-group contributions of the other groups (through the weights).

In the same line as in $T$, the between-group contribution of the other members of the Generalized Entropy family (for $\alpha \neq 0,1$ ) depends on overall between-group inequality, while the contribution to the within-group term depends on the group mean and overall within-group inequality:

$$
\begin{gathered}
S_{B}^{k}\left(I_{\alpha}\right)=\alpha\left(I_{B \alpha}+\frac{1}{\alpha(\alpha-1)}\right) \frac{n^{k}}{n} \frac{\mu-\mu^{k}}{\mu} \\
S_{W}^{k}\left(I_{\alpha}\right)=\frac{n^{k}}{n}\left[I_{\alpha}\left(\boldsymbol{y}^{k}\right)+\alpha \frac{n^{k}}{n}\left(1-\left(\frac{\mu^{k}}{\mu}\right)^{1+\alpha}\right) I_{W \alpha}\right] .
\end{gathered}
$$

\section{A discussion of alternative approaches}

In this section, I discuss alternative approaches to estimate the contribution of a subpopulation to inequality borrowed from the related literature that estimates the contribution of income factors (or sources). In general, the contributions will also inherit properties of the target inequality indices (e.g. replication and scale invariance).

The first approach, for the sake of simplicity will be referred to here as the marginal (factor) decomposition. It defines the contribution of a factor as the change in inequality after it has been removed. For example, comparing initial and final distributions has been a common way of assessing the redistributive effect of taxes (e.g. Kakwani 1977). This is quite intuitive but has some limitations. It assumes a specific path for adding the different factors in which the target comes last. This is sometimes called the first-round effect. If

\footnotetext{
${ }^{7}$ In other words, the total effect of $\mu^{k}$ on $T$ is given by $\frac{n^{k}}{n} R I F\left(\mu^{k}, T(\boldsymbol{y})\right)$, that can be split into the effect on the between-group component, $\frac{n^{k}}{n} \operatorname{RIF}\left(\mu^{k}, T_{B}\right)$, and the effect on the within-group term, $\frac{n^{k}}{n} T_{W}\left(\frac{\mu-\mu^{k}}{\mu}\right)$.
} 
other rounds or sequences are considered (the factor is the first, second, etc. to be added), the contributions will be path-dependent. Furthermore, it produces an inconsistent decomposition in which the contributions of all factors do not add up to total inequality (although they can be re-scaled accordingly). The same inconsistency applies to further disaggregation of that same factor.

A second approach is the Shapley decomposition (Chantreuil and Trannoy 2013; Shorrocks 2013). It is an extension of the marginal approach defined as the average of the marginal contributions obtained in all possible sequences (rounds) in which each factor can be introduced. The Shapley decomposition is consistent and path-independent, but it will vary with the level of disaggregation of the various factors. This latter shortcoming might be overcome assuming some hierarchy in the involved factors, ${ }^{8}$ although, in general, the Shapley decomposition (and its standard errors) might be cumbersome to compute in the presence of many groups and large samples.

In the analysis of income sources, there are at least two possible factors to be considered, each one imposing a different normalization property as it defines the situation in which the contribution is zero. The contribution of an income source (e.g. a tax or a benefit) to total inequality is the change in inequality after (i) removing the income source ('zero income' decomposition); or (ii) equalizing the income source among all individuals ('equalizing income' decomposition) (e.g. Sastre and Trannoy 2002). In the same spirit, these cases are adapted here. I define the marginal contribution of a group as the change in inequality after (i) removing the group from the population ('zero subpopulation' decomposition)'; or (ii) replacing the incomes of its members with the population mean ('equalizing subpopulation' decomposition). Note that the latter implies a double equalization, removing group inequality and removing the gap with the population mean, which seems reasonable in the context of additively decomposable indices. ${ }^{10}$ Other alternatives seem less reasonable, such as (i) setting group incomes to zero; and (ii) replacing the incomes of group members with the group mean. It would be hard to assume that a group does not contribute to inequality between groups in any of both situations.

Finally, we briefly consider a third alternative approach used in the factor decomposition literature, i.e. the natural decomposition rules of some inequality indices, such as the coefficient of variation (Shorrocks 1982 showed it had implications for other measures under various assumptions), or Gini and Theil (Morduch and Sicular 2002). In the first two cases, factor contributions can be further decomposed into the product of factor income shares, variability, and correlation with total incomes. This approach is index-specific (only applies to indices with a natural decomposition rule) and is somehow myopic, it does not fully account for the contribution of a factor as will be discussed below. ${ }^{11}$

\footnotetext{
${ }^{8}$ For example, using the Nested Shapley or the Owen decompositions, see the discussion in Chantreuil and Trannoy (2013) and in Charpentier and Mussard (2011).

${ }^{9}$ This has been implicitly used to measure the contribution of certain countries to global inequality (e.g. Sala-iMartin, 2006).

${ }^{10}$ While in the case of the Atkinson family the mean should be replaced as a reference by the equally distributed equivalent income, in the case of Gini one needs to take also into account that a group with the population mean income and no inequality still has an impact on overall inequality through overlapping with the other groups. This implies that the normalization property with the marginal and Shapley approaches may need to be adapted to the specific index, while in the case of RIF it is directly inherited from the index.

${ }^{11}$ I do not discuss here a more specific approach proposed by Rohde (2016) for the J-Divergence index.
} 


\subsection{The zero-subpopulation decomposition}

Let $y^{-k}=y \backslash y^{k}=\left(y^{1}, \ldots, y^{k-1}, y^{k+1}, \ldots, y^{K}\right)$ be the vector of the population remaining after removing group $k$, with the superscript $-k$ applied to any statistic derived from it. The marginal zero subpopulation contribution of group $k$ measures the impact of this removal on overall inequality:

$$
\gamma^{k}=I(y)-I\left(\boldsymbol{y}^{-k}\right)
$$

This contribution can take positive or negative values. The normalization property behind this approach is that the contribution of a group is zero when it is not part of the population. For $M$ and $T$, this is equivalent to the case in which the group has the same income mean and inequality of the rest, $\mu^{k}=\mu^{-k}$ and $I_{\alpha}\left(y^{k}\right)=I_{\alpha}\left(y^{-k}\right)$ because $^{12}$ :

$$
\gamma^{k}\left(I_{\alpha}\right)=I_{\alpha}\left(\left(\mu^{-k} \mathbf{1}_{\boldsymbol{n}^{-k}}, \mu^{k} \mathbf{1}_{\boldsymbol{n}^{k}}\right)\right)+w_{I_{\alpha}}^{k}\left(I_{\alpha}\left(\boldsymbol{y}^{\boldsymbol{k}}\right)-I_{\alpha}\left(\boldsymbol{y}^{-\boldsymbol{k}}\right)\right) \text { for } \alpha=0,1 .
$$

Thus, if all groups had the same inequality and mean, all contributions to $M$ or $T$ would be zero and none of the observed inequality could be attributed to any group. On the opposite side, if the population is made up of two homogenous groups, the contribution of both groups would be $I_{\alpha}$ (regardless of the group size). Although this approach is interesting to assess the importance of a specific group on overall inequality, it does not seem adequate for attributing to each group its share of the total level of inequality, which is the objective here.

The Shapley contribution will be the average of the two possible marginal contributions, depending on whether the group or the rest of the population is the first to be removed. ${ }^{13}$ The corresponding Shapley contributions is given by:

$$
\gamma^{\prime k}=\frac{1}{2}\left(I(\boldsymbol{y})+I\left(\boldsymbol{y}^{k}\right)-I\left(\boldsymbol{y}^{-k}\right)\right) .
$$

It is noteworthy that in both cases, in general, the differential between the contribution of one group and the rest of the population only depends on the differential in group inequality regardless of their population shares or relative incomes:

$$
\gamma^{k}-\gamma^{-k}=\gamma^{\prime k}-\gamma^{\prime-k}=I\left(\boldsymbol{y}^{\boldsymbol{k}}\right)-I\left(\boldsymbol{y}^{-\boldsymbol{k}}\right) .
$$

Therefore, a highly unequal (equal) group will have a disproportionally larger positive (negative) contribution to inequality compared with other groups, even if its share of the population is almost zero.

\subsection{The equalizing subpopulation decomposition}

Alternatively, the contribution of a group can be defined as the impact of replacing their incomes with the population mean:

\footnotetext{
${ }^{12}$ For any $\alpha$ in the Entropy family, the group inequality condition is that $w_{I_{\alpha}}^{k} I_{\alpha}\left(\boldsymbol{y}^{\boldsymbol{k}}\right)=\left(1-w_{I_{\alpha}}^{-k}\right) I_{\alpha}\left(\boldsymbol{y}^{-\boldsymbol{k}}\right)$ because: $\gamma^{k}\left(I_{\alpha}\right)=I_{\alpha}\left(\left(\mu^{-k} \mathbf{1}_{\boldsymbol{n}^{-\boldsymbol{k}}}, \mu^{k} \mathbf{1}_{\boldsymbol{n}^{k}}\right)\right)+w_{I_{\alpha}}^{k} I_{\alpha}\left(\boldsymbol{y}^{\boldsymbol{k}}\right)-\left(1-w_{I_{\alpha}}^{-k}\right) I_{\alpha}\left(\boldsymbol{y}^{-\boldsymbol{k}}\right)$.

${ }^{13}$ For simplicity, I only consider here the case in which one group is compared against the rest of the population. Sastre and Trannoy (2002) provide the specific formula that can be used for the computation of a Shapley decomposition with $K$ factors.
} 


$$
\delta^{k}=I(\boldsymbol{y})-I\left(\left(\boldsymbol{y}^{-\boldsymbol{k}}, \mu \mathbf{1}_{\boldsymbol{n}^{k}}\right)\right)
$$

This implies the same normalization property verified by the RIF decomposition of the Generalized Entropy family of indices discussed above. Therefore, a null contribution to these indices is obtained if the group has the population mean and zero group inequality, the latter being a more demanding condition than just the same inequality as in the rest of the population, required in the previous approach. Note that, in this case, the differential in the contribution between two groups will depend on the inequality differential and on means and population shares:

$$
\delta^{k}-\delta^{-k}=I\left(\left(\mu \mathbf{1}_{\boldsymbol{n}^{-k}}, \boldsymbol{y}^{\boldsymbol{k}}\right)\right)-I\left(\left(\boldsymbol{y}^{-\boldsymbol{k}}, \mu \mathbf{1}_{\boldsymbol{n}^{k}}\right)\right) .
$$

The contributions will not necessarily add up to the overall level of inequality, although they could be rescaled accordingly:

$$
\widetilde{\delta}^{k}=\delta^{k} \frac{I(\boldsymbol{y})}{\sum_{k=1}^{K} \delta^{k}} .
$$

The corresponding Shapley contribution is given by:

$$
\delta^{\prime k}=\frac{1}{2}\left(I(\boldsymbol{y})+I\left(\left(\mu \mathbf{1}_{n^{-k}}, \boldsymbol{y}^{k}\right)\right)-I\left(\left(\boldsymbol{y}^{-\boldsymbol{k}}, \mu \mathbf{1}_{\boldsymbol{n}^{k}}\right)\right)\right) .
$$

In the case of additively decomposable indices, mimicking the aggregate decomposition (between group $k$ and the rest of the population) we further split these contributions into the between-group and within-group components:

$$
\delta^{k}\left(I_{\alpha}\right)=\delta_{B}^{k}\left(I_{\alpha}\right)+\delta_{W}^{k}\left(I_{\alpha}\right) .
$$

With:

$$
\begin{gathered}
\delta_{B}^{k}\left(I_{\alpha}\right)=I_{\alpha}\left(\left(\mu^{-k} \mathbf{1}_{\boldsymbol{n}^{-k}}, \mu^{k} \mathbf{1}_{\boldsymbol{n}^{k}}\right)\right)-I_{\alpha}\left(\left(\mu^{-k} \mathbf{1}_{\boldsymbol{n}^{-k}}, \mu \mathbf{1}_{\boldsymbol{n}^{k}}\right)\right) . \\
\delta_{W}^{k}\left(I_{\alpha}\right)=w_{I_{\alpha}}^{k} I_{\alpha}\left(\boldsymbol{y}^{\boldsymbol{k}}\right)+\frac{n^{-k}}{n} \pi(\alpha) I_{\alpha}\left(\boldsymbol{y}^{-\boldsymbol{k}}\right) . \\
\text { where } \pi(\alpha)=\left(\left(\frac{\mu^{-k}}{\mu}\right)^{\alpha}-\left(\frac{\mu^{-k}}{\mu^{*}}\right)^{\alpha}\right) \text { and } \mu^{*}=\frac{n^{-k}}{n} \mu^{-k}+\frac{n^{k}}{n} \mu .
\end{gathered}
$$

The marginal equalizing subpopulation contribution to $M$ is approximately equal to the RIF contribution, with the same within-group term (given that $\pi(0)=0$ ), and with a similar between-group component (provided $\frac{n^{k}}{n} \frac{\mu^{-} \mu^{k}}{\mu}$ is small), using a well-known property of $\operatorname{logarithms}{ }^{14}$

$$
\delta_{B}^{k}(M)=\frac{n^{k}}{n} \ln \frac{\mu}{\mu^{k}}-\ln \left(1+\frac{n^{k}}{n} \frac{\mu-\mu^{k}}{\mu}\right) \approx S_{B}^{k}(M) .
$$

$\left.\overline{{ }^{14} \text { Note that } M\left(\left(\mu^{-k} \mathbf{1}_{n^{-k}}, \mu^{k} \mathbf{1}_{n^{k}}\right)\right.}\right)-M\left(\left(\mu^{-k} \mathbf{1}_{\boldsymbol{n}^{-}} \boldsymbol{k}, \mu \mathbf{1}_{\boldsymbol{n}}{ }^{\boldsymbol{k}}\right)\right)=\left(\frac{n^{k}}{n} \ln \frac{\mu}{\mu^{k}}+n \frac{-k}{\left.n \ln \frac{\mu}{\mu^{-k}}\right)-\left(\frac{n^{k}}{n} \ln \frac{\mu^{*}}{\mu}+n^{-k}\right.} n \ln \frac{\mu^{*}}{\mu^{-k}}\right)=\frac{n^{k}}{n \ln \frac{\mu}{\mu^{k}}}-\ln \frac{\mu^{*}}{\mu}$ $=\frac{n^{k}}{n} \ln \frac{\mu}{\mu^{k}}-\ln \left(1+\frac{n^{k}}{n} \frac{\mu-\mu^{k}}{\mu}\right)$, and $\ln (1+x) \approx x$ if $x$ is small, with $x=\frac{n^{k}}{n} \frac{n-\mu^{k}}{\mu}$. The two approaches will be closer if the marginal contributions are rescaled to add up to total inequality, as shown in the empirical illustration. 


$$
\delta_{W}^{k}(M)=\frac{n^{k}}{n} M^{k}=S_{W}^{k}(M) .
$$

A similar result can be obtained for the Shapley decomposition:

$$
\begin{gathered}
\delta_{B}^{\prime k}(M)=\frac{n^{k}}{n} \ln \frac{\mu}{\mu^{k}}+\frac{1}{2} \ln \left(\frac{1+\frac{n^{k}}{n} \frac{\mu^{k}-\mu}{\mu}}{1-\frac{n^{k}}{n} \frac{\mu^{k}-\mu}{\mu}}\right) \approx S_{B}^{k}(M) . \\
\delta_{W}^{\prime k}(M)=\frac{n^{k}}{n} M\left(\boldsymbol{y}^{k}\right)=S_{W}^{k}(M) ;
\end{gathered}
$$

While the direct contribution of each group to between-group inequality is the same in marginal, Shapley and RIF approaches, the indirect contribution (i.e. the impact of the group mean on the relative incomes of other groups) is non-linear in the case of the Shapley and marginal contributions, but linear in the case of RIF. Thus, the latter might be seen as a linear approximation of the former. It turns out that in the case of $M$, the index with the best additively decomposability properties, the RIF and the marginal and Shapley equalizing subpopulation decompositions are empirically equivalent, provided the $\frac{n^{k}}{n} \frac{\mu^{k}-\mu}{\mu}$ terms are small. One could only expect remarkable discrepancies in significant groups with an average income that is several times the population mean. The linearization that RIF imposes might be a reasonable assumption at least in the case of this index, bringing attractive properties at only a low price. These approaches may provide different results in other cases, like $T$, though. The empirical section will help to clarify this in practical terms.

\subsection{Natural decomposition rules}

If an index can be expressed as a weighted sum of incomes:

$$
I(\boldsymbol{y})=\sum_{i=1}^{n} a(\boldsymbol{y}) y_{i},
$$

then the contribution of a group can be defined by:

$$
\tau^{k}(I)=\sum_{j=1}^{n^{k}} a(\boldsymbol{y}) y_{j}^{k}
$$

$M$ does not belong to this class of indices. In the case of $T, a(y)=\frac{1}{n \mu} \ln \frac{y_{j}^{k}}{\mu}$ and the contribution is given by:

$$
\tau^{k}(T)=\frac{1}{n} \sum_{j=1}^{n^{k}} \frac{y_{j}^{k}}{\mu} \ln \frac{y_{j}^{k}}{\mu}=\frac{n^{k}}{n} \frac{\mu^{k}}{\mu} T^{k}+\frac{n^{k}}{n} \frac{\mu^{k}}{\mu} \ln \frac{\mu^{k}}{\mu}=S^{k}(T)-\frac{n^{k}}{n}\left(\frac{\mu-\mu^{k}}{\mu}\right)(T+1) .
$$

That is, the contribution does not measure the total effect of group incomes. It only considers the direct effect on total inequality, but not the indirect effect on the function $a(y)$. This is true of the natural decomposition of any index. In the case of $T$, this means to ignore the impact of the average group mean on the relative incomes of the rest of the population - that affects both terms, inequality between groups and within groups, the latter through changes in group 
income shares. Given that the RIF approach is more general and accounts for both direct and indirect effects, this approach does not seem especially attractive in this context.

\section{Empirical analysis}

\subsection{Data}

To illustrate the potential of the approach, I use the two most recent household budget surveys collected by the Instituto Nacional de Estatística (INE) in Mozambique: the Inquéritos ao Orçamento Familiar (IOF 2008/09 and 2014/15). Wellbeing is approximated using daily real per capita consumption (MEF/DEEF 2016), i.e. nominal consumption adjusted to correct for seasonal variation in prices, deflated by dividing by the contemporary poverty line.

The sample of the first survey consists of 10,832 households (51,177 individuals) interviewed between 2008 and 2009. The most recent survey is a pool of about 11,000 households interviewed up to three times between 2014 and 2015: 11,505 households $(58,342$ individuals $)$ in the first quarter, $10,372(50,770)$ in the second, and $11,315(55,198)$ in the third one.

For the analysis, I considered four types of subpopulations: consumption percentile groups, area of residence (rural or urban), province, and level of education attained by the household head. The analysis is focused on the $M$ index and the RIF decomposition, because of its attractive decomposability properties, although I also provide results for other indices and approaches.

\subsection{Total inequality and the contribution by percentile}

Inequality increased in Mozambique between 1996/97 and 2002/03, followed by stagnation between 2002/03 and 2008/09, to raise again between 2008/09 and 2014/15 (Gradín and Tarp 2019). The increase during the last period was of 0.053 with Gini $(13 \%)$ and 0.078 with $M$ (from 0.303 to $0.381,26 \%$ ), as reported in Table 2 also for other indices (the change was robust due to Lorenz dominance).

Figure 1 shows how the RIF values of different indices vary according to relative consumption. The RIF of $M$ is independent of the distribution, while for $T$ and Gini, they are based on the most recent distribution in Mozambique. The common U-pattern highlights the fact that the contribution to inequality increases with the distance from the average and is especially high for those standing out for either too low or too high consumption levels. Figure 1 also shows the higher sensitivity of $M$ and, especially, $T$ to higher relative consumption values compared with Gini (known to be more sensitive to central values), as well as the higher sensitivity of $M$ to values close to 0 . Figure 2 shows, accordingly, the contribution by percentile group to inequality in Mozambique in 2014/15 as measured by these three indices for comparison. ${ }^{15}$ Two figures are displayed. Figure 2 a shows the entire distribution, highlighting the disproportional contribution of the top, while in Fig. $2 b$ the distribution is truncated at percentile 98 to show more detail of the centre and bottom percentiles. Table 3 summarizes the results for specific percentile ranges for several indices.

${ }^{15}$ Previous analyses of RIF functions by percentiles can be found in Gradín (2016 and 2018) or Davies et al. (2017). 
Table 2 Consumption inequality

\begin{tabular}{lllllllllllll}
$\begin{array}{l}\text { Per capita Consumption } \\
\text { (Meticais) }\end{array}$ & Gini & $\mathrm{I}_{-1}$ & $\mathrm{I}_{0}=\mathrm{M}$ & $\mathrm{I}_{1}=\mathrm{T}$ & $\mathrm{I}_{2}$ & $\mathrm{~A}_{.25}$ & $\mathrm{~A}_{.50}$ & $\mathrm{~A}_{.75}$ & $\mathrm{~A}_{1}$ & $\mathrm{~A}_{2}$ \\
\hline 23.8 & 0.415 & 0.409 & 0.303 & 0.367 & 0.887 & 0.082 & 0.150 & 0.209 & 0.262 & 0.450 \\
47.1 & 0.468 & 0.532 & 0.381 & 0.520 & 2.242 & 0.111 & 0.194 & 0.261 & 0.317 & 0.516 \\
\hline
\end{tabular}

$2008 / 0923.8$

Source: Author's calculations based on IOF 2008/09-2014/15

The largest contributions to $M$ came from the highest and, to a lesser extent, from the lowest percentile groups. This has the implication that in the analysis by other subpopulation groups, in the next epigraph, the average contribution will tend to be larger for those groups that are overrepresented at the top of the consumption scale. However, it is also noticeable that the range of lower percentiles with a significant contribution is longer and thus large groups with most of the population at the bottom of consumption levels will also have an important contribution to overall $M$ inequality. On the other hand, people (and groups) around the mean consumption level (around percentile 73) do not contribute at all to inequality with $M$.

More specifically, the contribution of the top 5\% population to $M$ is almost $42 \%$, not only much higher than their demographic weight (indicating large per capita contributions), but also higher than their contribution to total consumption (28.5\%). The consumption share of a group is also its relative contribution to the population mean and, thus, a marginal increase in the proportion of people at the top of the distribution increases $M$ relatively more than the mean. The contribution of the bottom $5 \%$ is also above its demographic weight, $14.5 \%$ (with only

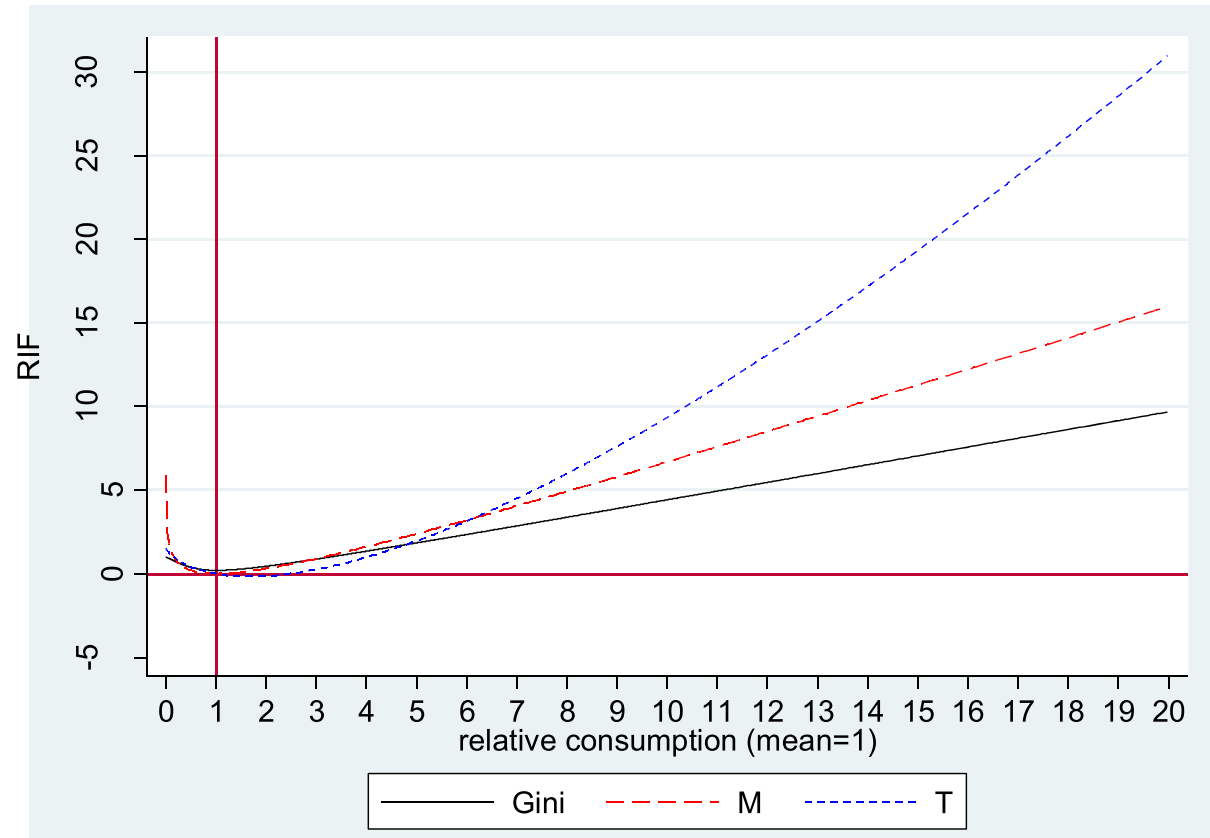

Fig. 1 RIF of relative consumption for $M, T$ and Gini Note: The RIF of $M$ is independent of the distribution. RIF of $T(T=0.520)$ and Gini are computed for Mozambique 2014/15. Source: Author's calculations based on IOF $2014 / 15$ 


\section{a: Untruncated}

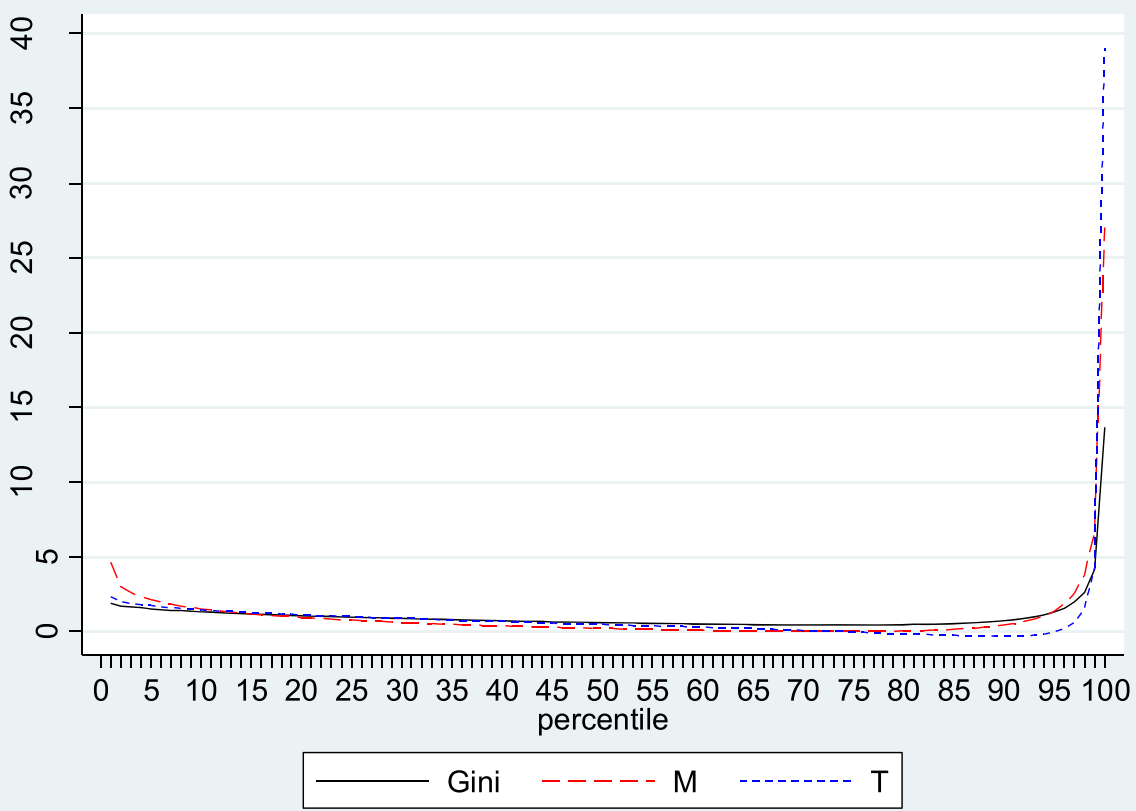

b: Truncated at percentile 98

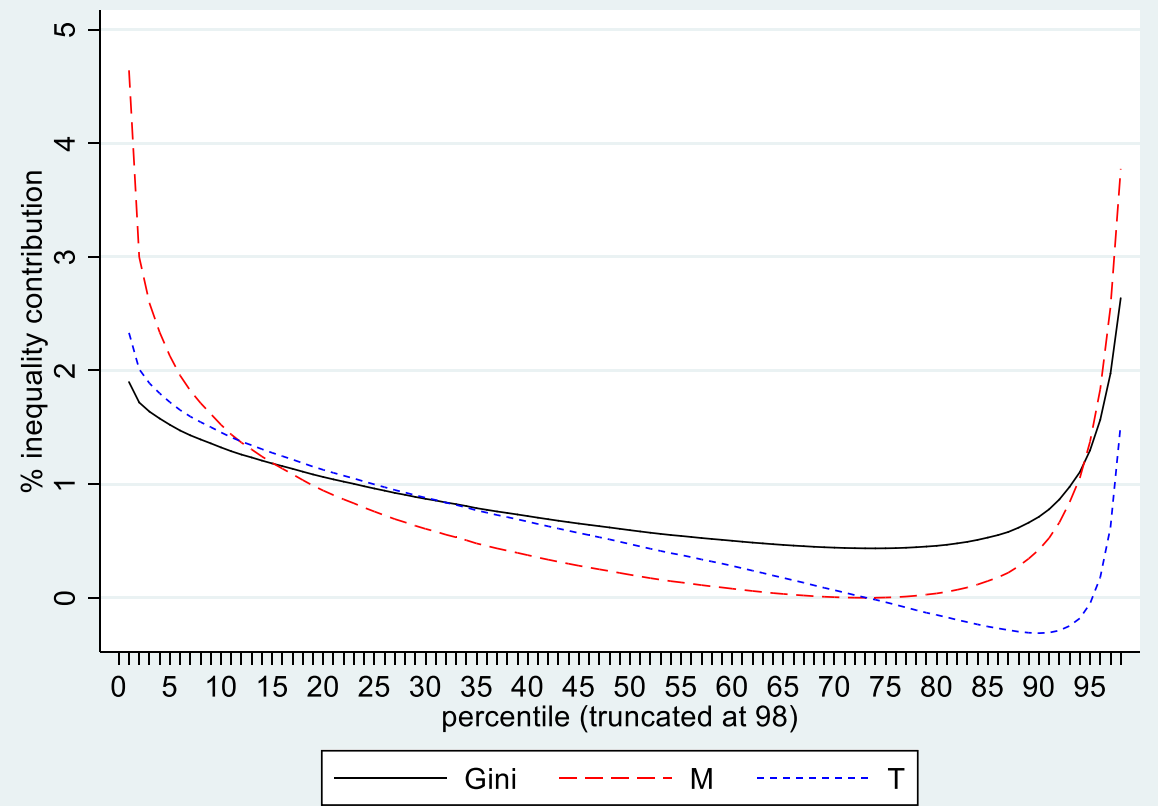

Fig. 2 Relative contributions to inequality by percentile group, 2014/15 2a: Untruncated, 2b: Truncated at percentile 98 Source: Author's calculations based on IOF 2014/15 


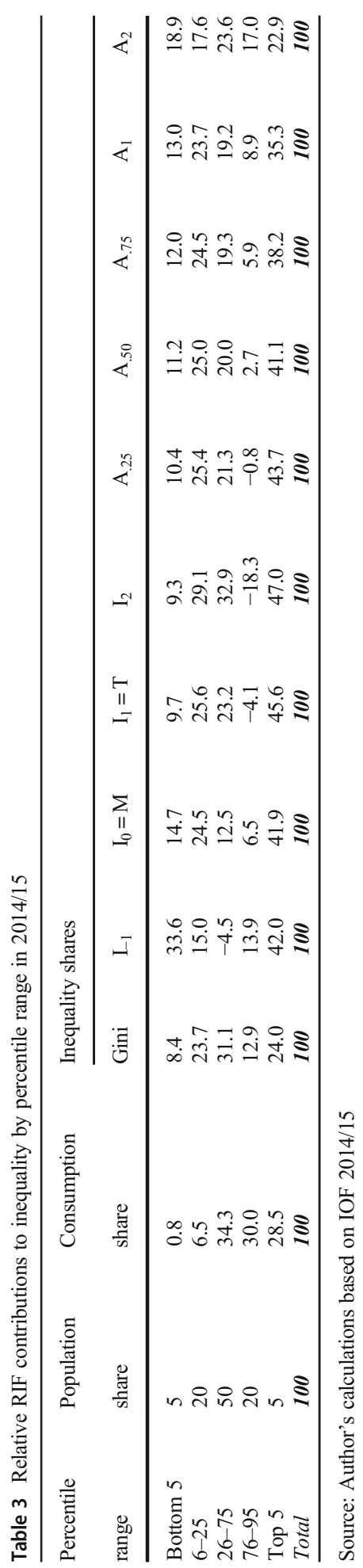




\section{a: Untruncated}

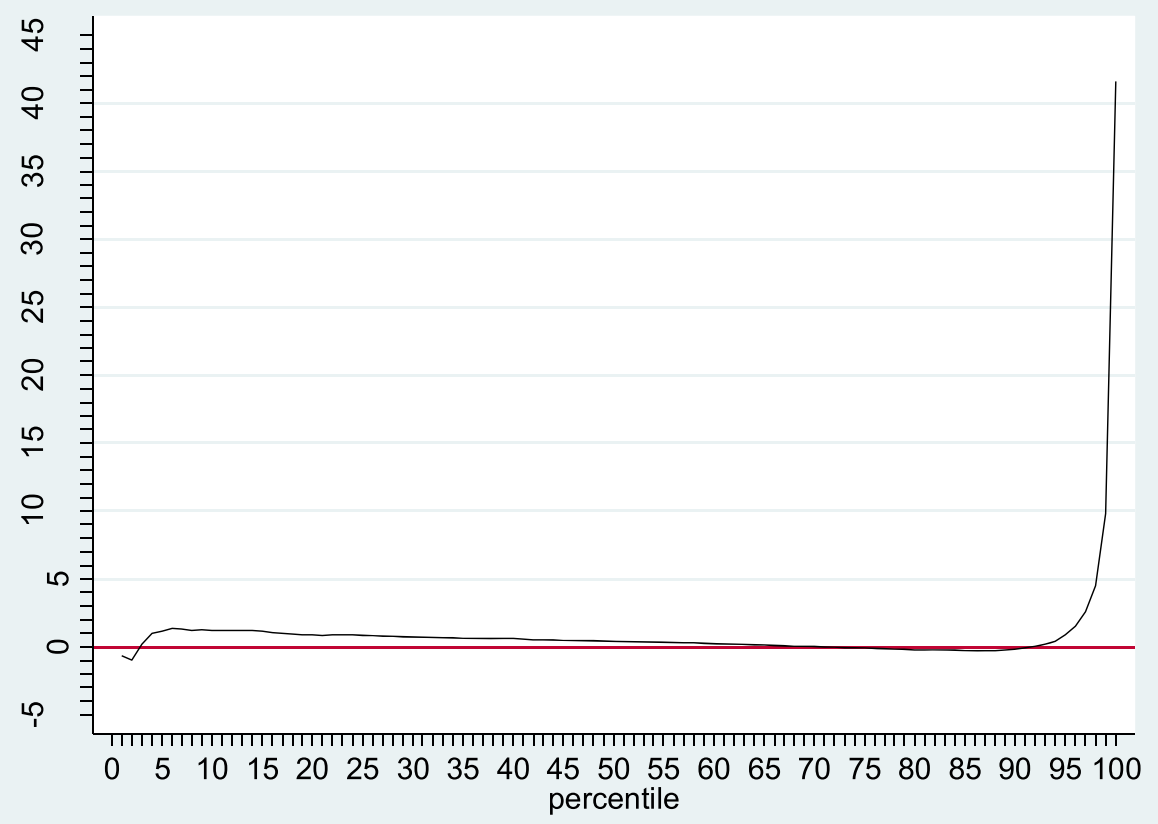

b: Truncated at percentile 98

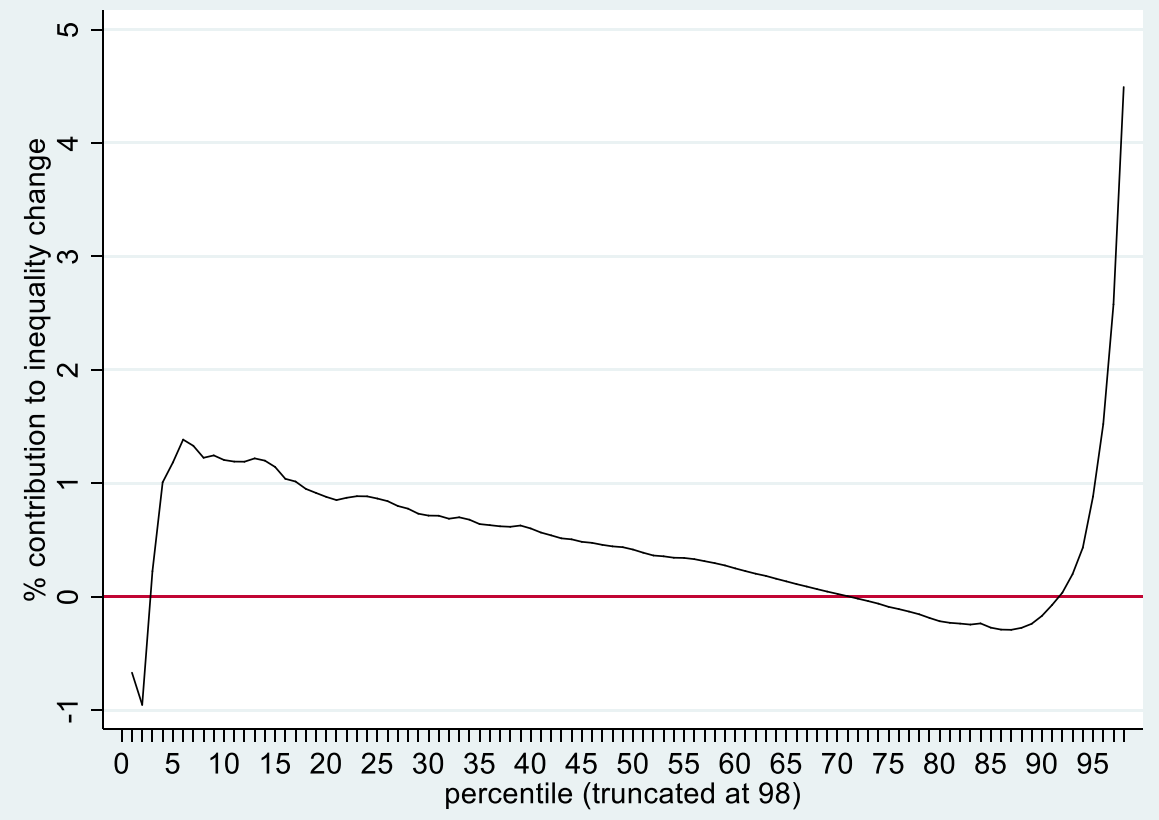

Fig. 3 Relative contributions to inequality increase $(M)$ by percentile group, 2008/09-2014/15 3a: Untruncated, 3b: Truncated at percentile 98 Source: Author's calculations based on IOF 2008/09-2014/15 


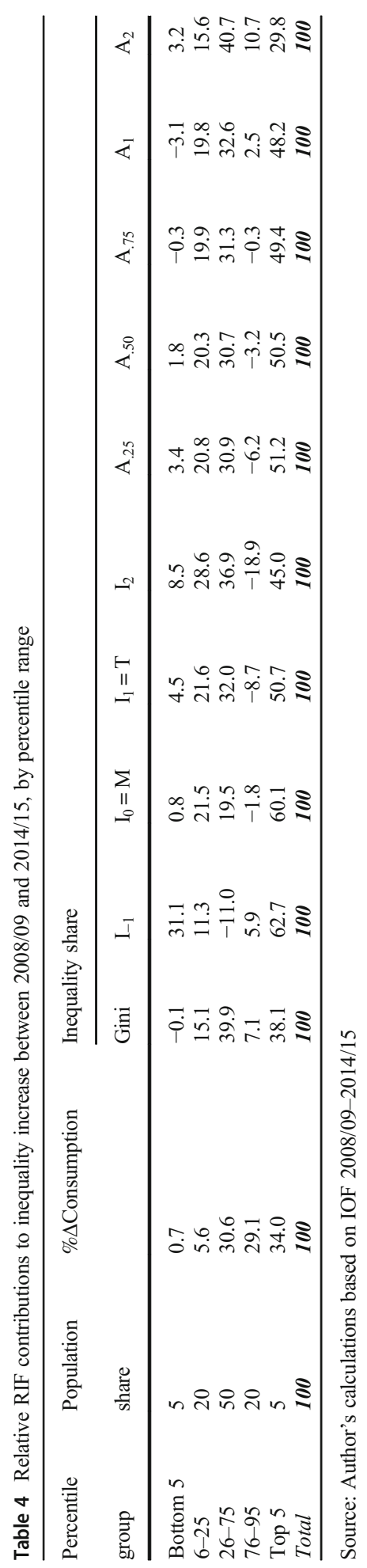




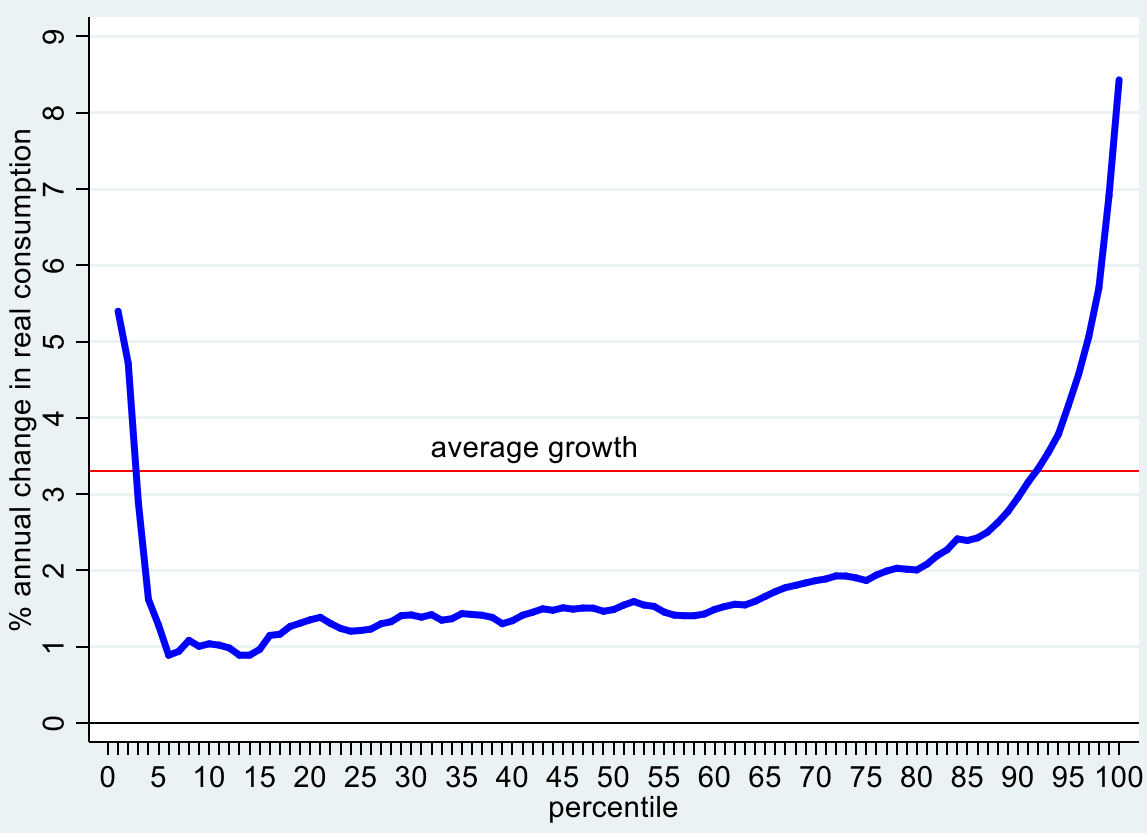

Fig. 4 Growth incidence curve by percentile group, percentage of annual increase in real consumption 2008/092014/15 Source: Author's calculations based on IOF 2008/09-2014/15

$0.8 \%$ of total consumption). That is, both extremes, with only $10 \%$ of the population altogether, contribute to almost $57 \%$ of total inequality. On the opposite side, the contributions fall below $1 \%$ between percentiles 20 th and $93 \mathrm{rd}$.

As for the other indices, the relative contributions of both poorest and richest percentiles are smaller with the Gini index (e.g. 8.4 and $24 \%$ for the bottom and top $5 \%$, respectively). While the contribution of the poorest percentiles is also smaller with $T$ (near $10 \%$ ) than with $M$, the contribution of the very richest is even higher: $45.6 \%$, but not as much as for $I_{2}$. The Atkinson family presents the expected results, lower contribution of the richest and higher of the poorest for higher values of the inequality aversion parameter. It is interesting to notice that among all the indices displayed in Table 3, the contribution of the bottom 5\% is lowest in the case of the Gini index, and so is the contribution of the top $5 \%$ (except for the case in which aversion to inequality is 2 in the Atkinson family). The contribution of the top 5\% is below their contribution to total consumption, unlike what is observed in other indices. This means that a marginal increase in the proportion of population at the top produces a larger impact on the mean than on the Gini index and on the Atkinson with high inequality aversion, a good indication of how these two are less sensitive to the top tail than other measures.

The most relevant empirical analysis, however, is explaining the trend in inequality over time (between 2008/09-2014/15), shown in Fig. 3 and Table 4. Figure 3a shows the relative contributions along the entire percentile range, while Fig. $3 \mathrm{~b}$ is truncated at percentile 98 to highlight changes in the middle and bottom of the distribution. It is noticeable that this curve is just a simple transformation of the classical growth incidence 


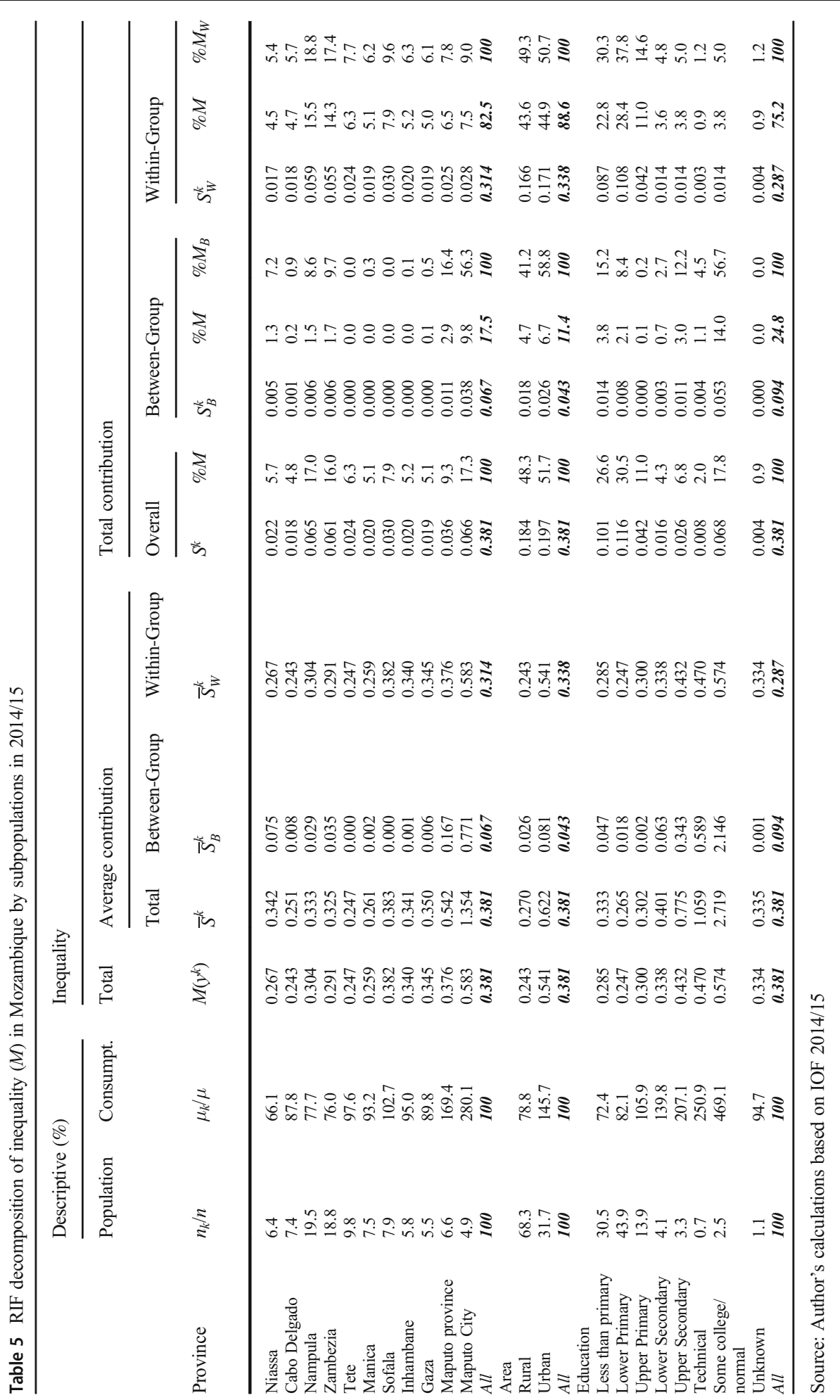




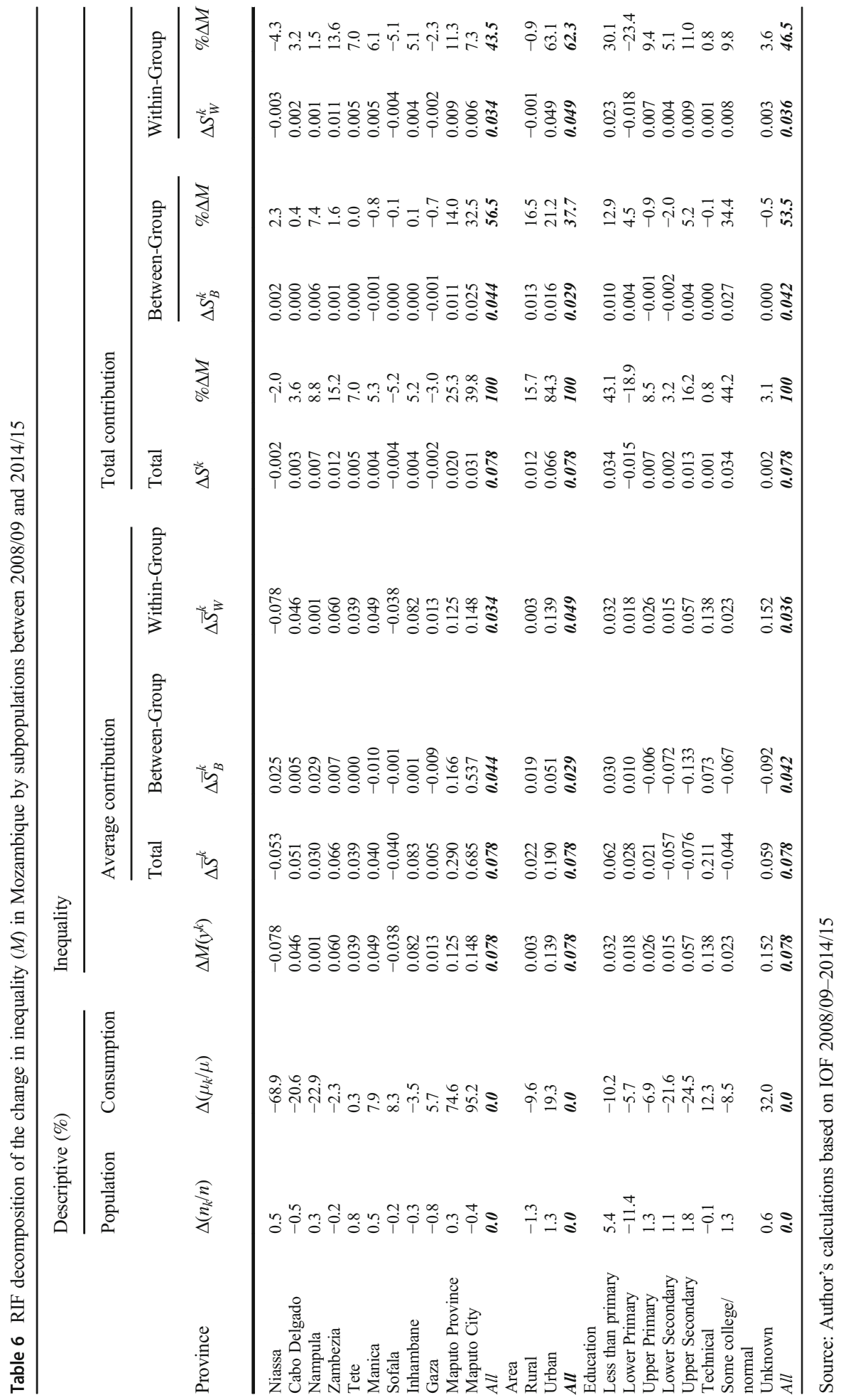


curve (in Fig. 4) to reflect the impact on inequality of the relative consumption growth experienced along the different percentiles. The contribution of a percentile to the change in inequality will be positive or negative depending on how it performed compared to the average growth: inequality-enhancing changes for percentiles moving away from the average, inequality-reducing changes for those moving closer to the average.

The clear pro-rich growth pattern in consumption (Fig. 4) implied that about $60 \%$ of the increase in $M$ was associated with a larger contribution of the top 5\% (42\% in the top $1 \%$ ), the result of. On the other side, the bottom $5 \%$ of the consumption distribution only contributed with less than $1 \%$ of the inequality increase. Contributions to the change in inequality were indeed slightly negative in the first two percentiles, as they were between percentiles 74 and 91 . The contribution of the rich is much smaller but still significant in the case of Gini $(38 \%)$ and declines with inequality aversion in the case of the Atkinson family.

\subsection{Analysis by other subpopulations}

Table 5 reports the conventional aggregate additive decomposition of $M$ in 2014/15 by province, area of residence and head's education (rows labelled as 'All'). For example, total inequality $(0.381)$ can be split into the two corresponding between-province $(0.067,17.5 \%)$ and within-province $(0.314,82.5 \%)$ terms. Table 5 also reports the more detailed RIF decomposition, showing that the capital Maputo city, representing only $5 \%$ of the total population or $14 \%$ of total consumption, disproportionally contributed with $17 \%$ of total inequality in that year, of which almost 10 percentage points were through the between-group component (56\% of the overall between-group component). The large contribution of Maputo city was the result of combining two facts. It is the richest among all provinces (per capita consumption is 2.8 times the national average), influencing its between-group contribution. It has the highest level of inequality too (within-group term). Something similar is found in Maputo province, even if to a lesser extent. With near $7 \%$ of the population (and $11 \%$ of consumption) Maputo province contributes with $9 \%$ of total inequality, $3 \%$ through the between-group component, and $6 \%$ through the within-group component.

On the other hand, northern provinces of Zambézia and Nampula show similar contributions of 16 and $17 \%$ of total inequality, respectively. But in these cases, the large contribution is the result of these provinces representing near $20 \%$ of the population each. Indeed, they show an average RIF below the mean because their relative consumption levels are the lowest (78 and $76 \%$ of the average), with intermediate inequality levels $(0.304$ and 0.291$)$. Thus, their contributions came almost entirely from the within-group component, to which they are the largest contributors (near $15 \%$ each) given their large population sizes.

In the middle between both extremes, other provinces like Niassa, Sofala, Inhambane, or Gaza, have a total contribution only slightly below their corresponding population shares. Not surprisingly, some provinces, with consumption levels around $87-103 \%$ of the national average have a negligible contribution to between-group inequality, while only the richest ones, as mentioned above Maputo city and province, and the poorest (Niassa, Nampula and Zambézia with 1.3-17\%) report substantial contributions through this component. Similarly, and consistently with the discussion above, urban and rural areas contribute about a half each to total inequality, although in 
Table 7 Relative Decompositions (per cent) of overall inequality ( $M$ and $T$ ) by subpopulation, Mozambique 2014/15

\begin{tabular}{|c|c|c|c|c|c|c|}
\hline \multirow[b]{2}{*}{ Percentiles } & \multicolumn{3}{|l|}{$M$} & \multicolumn{3}{|l|}{$T$} \\
\hline & $\begin{array}{l}\text { RIF } \\
S^{k}\end{array}$ & $\begin{array}{l}\text { Marginal }^{*} \\
\widetilde{\delta}^{k}\end{array}$ & $\begin{array}{l}\text { Shapley } \\
\delta^{\prime k}\end{array}$ & $\begin{array}{l}\text { RIF } \\
S^{k}\end{array}$ & $\begin{array}{l}\text { Marginal }^{*} \\
\widetilde{\delta}^{k}\end{array}$ & $\begin{array}{l}\text { Shapley } \\
\delta^{\prime k}\end{array}$ \\
\hline Bottom 5\% & 14.7 & 12.9 & 14.5 & 9.7 & 8.0 & 7.3 \\
\hline $6-25$ & 24.5 & 23.1 & 23.8 & 25.6 & 20.2 & 17.5 \\
\hline $26-75$ & 12.5 & 13.3 & 11.7 & 23.2 & 18.5 & 13.5 \\
\hline $76-95$ & 6.5 & 6.8 & 7.0 & -4.1 & -2.9 & 1.8 \\
\hline Top 5\% & 41.9 & 43.7 & 43.0 & 45.6 & 56.3 & 59.9 \\
\hline All & 100 & 100 & 100 & 100 & 100 & 100 \\
\hline \multicolumn{7}{|l|}{ Province } \\
\hline Niassa & 5.7 & 5.7 & 5.7 & 5.3 & 5.1 & 4.1 \\
\hline Cabo Delgado & 4.8 & 4.8 & 4.8 & 4.7 & 4.5 & 4.2 \\
\hline Nampula & 17.0 & 17.0 & 17.0 & 20.0 & 18.9 & 17.8 \\
\hline Zambezia & 16.0 & 16.0 & 16.0 & 14.8 & 14.0 & 12.5 \\
\hline Tete & 6.3 & 6.2 & 6.3 & 5.2 & 5.0 & 5.1 \\
\hline Manica & 5.1 & 5.0 & 5.1 & 4.5 & 4.4 & 4.3 \\
\hline Sofala & 7.9 & 7.8 & 7.9 & 7.3 & 7.2 & 7.4 \\
\hline Inhambane & 5.2 & 5.1 & 5.2 & 4.7 & 4.6 & 4.5 \\
\hline Gaza & 5.1 & 5.0 & 5.1 & 4.6 & 4.5 & 4.3 \\
\hline Maputo province & 9.3 & 9.4 & 9.4 & 7.8 & 8.2 & 10.1 \\
\hline Maputo City & 17.3 & 18.0 & 17.4 & 21.2 & 23.5 & 25.6 \\
\hline All & 100 & 100 & 100 & 100 & 100 & 100 \\
\hline \multicolumn{7}{|l|}{ Area } \\
\hline Rural & 48.3 & 48.2 & 48.1 & 46.6 & 39.5 & 38.7 \\
\hline Urban & 51.7 & 51.8 & 51.9 & 53.4 & 60.5 & 61.3 \\
\hline All & 100 & 100 & 100 & 100 & 100 & 100 \\
\hline \multicolumn{7}{|l|}{ Education } \\
\hline Less than primary & 26.6 & 26.7 & 26.5 & 27.5 & 25.8 & 23.1 \\
\hline Lower Primary & 30.5 & 30.4 & 30.5 & 28.7 & 26.9 & 24.6 \\
\hline Upper Primary & 11.0 & 10.7 & 11.0 & 9.1 & 9.1 & 9.6 \\
\hline Lower Secondary & 4.3 & 4.2 & 4.3 & 3.2 & 3.2 & 4.0 \\
\hline Upper Secondary & 6.8 & 6.8 & 6.8 & 6.8 & 7.2 & 8.7 \\
\hline Technical & 2.0 & 2.0 & 2.0 & 1.9 & 1.9 & 2.4 \\
\hline $\begin{array}{l}\text { Some college/ } \\
\text { normal }\end{array}$ & 17.8 & 18.4 & 17.9 & 22.1 & 25.1 & 26.8 \\
\hline Unknown & 0.9 & 0.9 & 0.9 & 0.8 & 0.8 & 0.8 \\
\hline All & 100 & 100 & 100 & 100 & 100 & 100 \\
\hline
\end{tabular}

Note: (*) Marginal approach normalized so that group contributions add up to total inequality

Source: Author's calculations based on IOF 2014/15

the case of urban areas this is due to a higher average RIF, because they make up less than a third of the population.

The analysis by the level of education attained by the household head shows that the small group of people in households whose head had some college contributed with $18 \%$ of inequality, despite being only $2.5 \%$ of the population. This contribution occurs mostly through the between-group component (14\% of total inequality), because mean consumption is almost 5 times the average. This group is also the most unequal, but given its small size only makes a small contribution to the within-group component (4\%, still above its population share). Educational groups below secondary education, on the contrary, contribute to inequality below their share of the population. 
Table 8 RIF decomposition of inequality $(T)$ in Mozambique by subpopulations in 2014/15

\begin{tabular}{|c|c|c|c|c|c|c|c|c|c|c|c|c|}
\hline \multirow[b]{4}{*}{ Province } & \multicolumn{12}{|c|}{ Inequality } \\
\hline & \multirow{3}{*}{$\begin{array}{l}\text { Index } \\
T\left(y^{k}\right)\end{array}$} & \multicolumn{3}{|c|}{ Average contribution } & \multicolumn{8}{|c|}{ Total contribution } \\
\hline & & \multirow{2}{*}{$\begin{array}{l}\text { Total } \\
\bar{S}^{k}\end{array}$} & \multirow{2}{*}{$\begin{array}{l}\text { Between } \\
\text {-Group } \\
\bar{S}_{B}^{k}\end{array}$} & \multirow{2}{*}{$\begin{array}{l}\text { Within } \\
\text {-Group } \\
\bar{S}_{W}^{k}\end{array}$} & \multicolumn{2}{|c|}{ Overall } & \multicolumn{3}{|c|}{ Between-Group } & \multicolumn{3}{|c|}{ Within-Group } \\
\hline & & & & & $\begin{array}{l}\text { Abs. } \\
S^{k}\end{array}$ & $\begin{array}{l}\% \\
\% T\end{array}$ & $\begin{array}{l}\text { Abs. } \\
S_{B}^{k}\end{array}$ & $\begin{array}{l}\% \\
\% T\end{array}$ & $\% T_{B}$ & $\begin{array}{l}\text { Abs. } \\
S_{W}^{k}\end{array}$ & $\begin{array}{l}\% \\
\% T\end{array}$ & $\% T_{W}$ \\
\hline Niassa & 0.280 & .427 & & 0.334 & & 5.3 & & & 7.2 & 0.021 & 4.1 & 4.9 \\
\hline Cabo Delgado & 0.295 & 0.331 & 0.018 & 0.313 & 0.024 & 4.7 & 0.001 & 0.3 & 1.6 & 0.023 & 4.4 & 5.3 \\
\hline Nampula & 0.502 & 0.533 & 0.045 & 0.488 & 0.104 & 20.0 & 0.009 & 1.7 & 10.7 & 0.095 & 18.3 & 21.7 \\
\hline Zambezia & 0.333 & 0.410 & 0.051 & 0.358 & 0.077 & 14.8 & 0.010 & 1.9 & 11.7 & 0.067 & 12.9 & 15.4 \\
\hline Tete & 0.269 & 0.275 & 0.002 & 0.273 & 0.027 & 5.2 & 0.000 & 0.0 & 0.3 & 0.027 & 5.1 & 6.1 \\
\hline Manica & 0.298 & 0.316 & 0.008 & 0.308 & 0.024 & 4.5 & 0.001 & 0.1 & 0.7 & 0.023 & 4.4 & 5.3 \\
\hline Sofala & 0.481 & 0.481 & -0.002 & 0.483 & 0.038 & 7.3 & 0.000 & 0.0 & -0.2 & 0.038 & 7.3 & 8.7 \\
\hline Inhambane & 0.410 & 0.417 & 0.005 & & 0.024 & 4.7 & 0.000 & 0.1 & & 0.024 & 4.6 & 5.5 \\
\hline Gaza & 0.415 & 0.431 & 0.014 & 0.418 & 0.024 & 4.6 & 0.001 & 0.1 & 0.9 & 0.023 & 4.4 & 5.3 \\
\hline Maputo province & 0.461 & 0.618 & 0.142 & 0.477 & 0.041 & 7.8 & 0.009 & 1.8 & 11.3 & 0.031 & 6.0 & 7.1 \\
\hline Maputo City & 0.755 & 2.262 & 0.935 & 1.327 & 0.110 & 21.2 & 0.046 & 8.8 & 55.3 & 0.065 & 12.4 & 14.8 \\
\hline $\begin{array}{l}\text { All } \\
\text { Area }\end{array}$ & 0.520 & 0.520 & 0.082 & 0.438 & 0.520 & 100 & 0.082 & 15.8 & 100 & 0.438 & 84.2 & 100 \\
\hline Rural & 279 & 0.354 & 0. & 0 & 12 & 46.6 & 0.0 & 4.5 & 50.8 & 0. & 42.1 & 46.2 \\
\hline Urban & 0.703 & 0.878 & 0.071 & 0.807 & 0.278 & 53.4 & 0.022 & 4.3 & 49.2 & 0.255 & 49.1 & 53.8 \\
\hline $\begin{array}{l}\text { All } \\
\text { Education }\end{array}$ & 0.520 & 0.520 & 0.046 & 0.474 & 0.520 & 100 & 0.046 & 8.8 & 100 & 0.474 & 91.2 & 100 \\
\hline Less than pr & 0.390 & 0.468 & 0. & 0 & & 27.5 & 0.024 & 4.6 & 18.2 & 0.119 & 22.8 & 30.6 \\
\hline Lower Primary & 0.280 & 0.340 & 0.041 & 0.299 & 0.149 & 28.7 & 0.018 & 3.4 & 13.5 & 0.131 & 25.2 & 33.9 \\
\hline Upper Primary & 0.349 & 0.340 & -0.006 & 0.346 & 0.047 & 9.1 & -0.001 & -0.2 & -0.6 & 0.048 & 9.3 & 12.5 \\
\hline Lower Secondary & 0.387 & 0.404 & 0.018 & 0.386 & 0.017 & 3.2 & 0.001 & 0.1 & 0.5 & 0.016 & 3.0 & 4.1 \\
\hline Upper Secondary & 0.571 & 1.063 & 0.294 & 0.768 & 0.036 & 6.8 & 0.010 & 1.9 & 7.4 & 0.026 & 4.9 & 6.6 \\
\hline Technical & 0.532 & 1.349 & 0.599 & 0.751 & 0.010 & 1.9 & 0.004 & 0.8 & 3.2 & 0.005 & 1.0 & 1.4 \\
\hline $\begin{array}{l}\text { Some college/ } \\
\text { normal }\end{array}$ & 0.632 & 4.605 & 3.071 & 1.534 & 0.115 & 22.1 & 0.077 & 14.7 & 57.7 & 0.038 & 7.4 & 9.9 \\
\hline Unknown & 0.382 & 0.390 & 0.008 & & & 0.8 & 0.000 & 0.0 & 0.1 & 0.004 & 0.8 & 1.0 \\
\hline All & 0.520 & 0.520 & 0.133 & 0.387 & 0.520 & 100 & 0.133 & 25.5 & 100 & 0.387 & 74.5 & 100 \\
\hline
\end{tabular}

Source: Author's calculations based on IOF 2014/15

The role of each of these subpopulations in explaining the increase of 0.078 in overall inequality between 2008/09 and 2014/15 is reported in Table $6 .{ }^{16}$ Overall, more than half the increase in inequality was between provinces, but also with a substantial increase within provinces. Maputo city and province, alone, are responsible for two thirds of the increase in inequality over this period (39.8 and 25.3 respectively). This is primarily the result of their higher contribution to inequality between groups (due to the significant increase in per capita consumption and thus in their average contribution to this term, especially in Maputo city). To a lesser extent, it is also the result of their higher contribution to the within-group term (due to the substantial increase in inequality within these two areas). Zambézia also explains $15 \%$ of the increase in inequality, in this case almost entirely because of the increase in the level of inequality in this province. Niassa and Sofala show negative contributions due to the fall in inequality, while the negative contribution of Gaza is associated with its loss of population.

\footnotetext{
${ }^{16}$ In Gradín and Tarp (2019) using RIF regressions controlling for several characteristics at the same time, higher education of household heads was identified as the most relevant driving factor of increasing inequality, along more heads working in the private non-subsistence sector of the economy.
} 
In the same line, only about $20 \%$ of the increase in inequality is between urban and rural areas. Urban areas explained $84 \%$ of the total increase in overall inequality, but in this case, it is inequality within these areas that dominates (63 of the increase, compared with $21 \%$ in the between-group case). Furthermore, more than half the increase in inequality was between educational groups, with the responsibility being more bipolarized in this case. The lowest educated group contributes to $43 \%$ of the increase, especially due to the within-group component $(30 \%)$, the highest educated to another $44 \%$, especially to the between-group term $(34 \%) .^{17}$

Table 7 shows that, as expected, the contributions to $M$ computed using the marginal and Shapley equalizing subpopulation approaches are almost identical to RIF contributions described above, with only non-negligible differences for the contribution of the very richest (top 5 percentile group).

The results for RIF using $T$, instead of $M$, to measure inequality are reported in Table 8. In this case, not surprisingly, the contribution of richest groups to the withingroup inequality tends to be higher than with $M$ because of their higher relative weight (income share instead of population share). For example, the total contribution of Maputo city is now 21\%, 9\% through the between-group component, 12 through the within-group. In the same line, the contribution to the intra-group component made by households whose head has some college education has now doubled (7\%). The marginal and, to a lesser extent, the Shapley contributions to $T$ are also not too far from the RIF values (Table 7), although in this case they diverge more than they did for $M$. Especially, they tend to increase even further the contribution of richest groups, like the top 5 percentile groups or urban areas (and decrease those of poorest groups).

\section{Concluding remarks}

I proposed here a detailed decomposition of inequality indices by subpopulations, in which overall inequality can be decomposed into the contribution of the distinct groups making up the population. In the case of additively decomposable inequality indices, these contributions can be further decomposed into their between-group and within-group components. The main approach is based on the RIF of the corresponding inequality index, that extends the classical aggregate decomposition to identify the main drivers of inequality, in a way that is also consistent with the RIF regression-based decomposition of changes in inequality into compositional and structural effects.

The RIF detailed decomposition is straightforward to compute and is shown to verify several appealing properties, such as consistency, path independence, and independence on the level of aggregation among others. However, there are other natural alternatives in the related literature of factor decomposition that can be considered and that do not impose such linearity. I argue that the marginal or Shapley decompositions using the equalizing subpopulation approach are the most relevant tool to attribute the contribution to inequality by subpopulations of additively decomposable indices. They assume that a group with all incomes equal to the

\footnotetext{
${ }^{17}$ A different analysis would be to produce a Blinder-Oaxaca decomposition of the changes in the group contributions over time into changes in group population shares (compositional effect) and changes in the average contributions (structural effect), as explained in the methodological section. This is not done here because population changes were relatively small in the short period analyzed and most changes can be presumably driven by changes in the average contributions.
} 
population average does not contribute to inequality. I also show that RIF, marginal and Shapley approaches are approximately equal in the case of the Mean Log Deviation, the only index that is additively decomposable and whose decomposition is more genuine and invariant to the path followed to break inequality into between- and within-group components. In other cases, RIF and the other approaches might differ.

The approach was illustrated with an empirical analysis of consumption inequality in Mozambique, a very poor and highly unequal country in sub-Saharan Africa that has shown an increasing trend in recent years. The analysis confirms that the choice of approach is not empirically relevant when it comes to decompose the Mean Log Deviation using the same normalization property. The richest groups, such as people living in Maputo or in other urban areas, with higher educational level, or in the top of the consumption distribution are responsible for the largest shares of inequality and for its increasing trend over time. The value assigned to the contribution of these richest groups to inequality, however, tends to be even higher in the case of the Shapley decomposition compared with RIF when the Theil index is used instead, even if the qualitative results are very similar.

As a final remark, it is interesting to note that one application of this approach is estimating the impact of top incomes (either reported or adjusted) on inequality levels and trends. This can be done for affluent people in general or for specific rich groups, while using aggregate indices of inequality that make the most of the information on the entire distribution, unlike other statistics based only on partial information obtained from incomes at specific quantiles. This helps to analyse one of the topics that are becoming more relevant in the inequality literature (e.g. Atkinson 2005) using the conventional framework of measuring inequality.

Acknowledgements This study has been prepared within the project on 'Inclusive growth in Mozambique - scaling-up research and capacity' implemented in collaboration between UNU-WIDER, University of Copenhagen, University Eduardo Mondlane, and the Mozambican Ministry of Economics and Finance. The project is financed through specific programme contributions by the governments of Denmark, Finland, Norway, and Switzerland.

Open Access The opinions expressed in this publication are those of the authors/editors and do not necessarily reflect the views of the UNU-WIDER, its Board of Directors, or the countries they represent. This book is licensed under the terms of the Creative Commons Attribution-NonCommercial-ShareAlike 3.0 IGO License (https://creativecommons.org/licenses/by-nc-sa/3.0/igo/), which permits any noncommercial use, sharing, adaptation, distribution, and reproduction in any medium or format, as long as you give appropriate credit to the UNU-WIDER, provide a link to the Creative Commons licence and indicate if changes were made. If you remix, transform, or build upon this book or a part thereof, you must distribute your contributions under the same licence as the original. The use of the UNU-WIDER's name, and the use of the UNU-WIDER's logo, shall be subject to a separate written licence agreement between the UNU-WIDER and the user and is not authorized as part of this CC-IGO licence. Note that the link provided above includes additional terms and conditions of the licence. The images or other third party material in this book are included in the book's Creative Commons licence, unless indicated otherwise in a credit line to the material. If material is not included in the book's Creative Commons licence and your intended use is not permitted by statutory regulation or exceeds the permitted use, you will need to obtain permission directly from the copyright holder. 


\section{References}

Atkinson, A.B.: Comparing the distribution of top incomes across countries. J. Eur. Econ. Assoc. 3(2-3), 393401 (2005)

Bhattacharya, N. and B. Mahalanobis: Regional disparities in household consumption in India. J. Am. Stat. Assoc. 62(317), 143-161 (1967)

Blackorby, C., Donaldson, D., Auersperg, M.: A new procedure for the measurement of inequality. Can. J. Econ. 14(4), 665-685 (1981)

Blinder, A.S.: Wage discrimination: reduced form and structural estimates. J. Hum. Resour. 8(4), 436-455 (1973)

Bourguignon, F.: Decomposable income inequality measures. Econometrica. 47(4), 901-920 (1979)

Chakravarty, S.R.: Inequality, Polarization and Poverty: Advances in Distributional Analysis. Springer, New York (2009)

Chantreuil, F., Trannoy, A.: Inequality decomposition values: the trade-off between marginality and efficiency. J. Econ. Inequal. 11(1), 83-98 (2013)

Charpentier, A., Mussard, S.: Income inequality games. J. Econ. Inequal. 9(4), 529-554 (2011)

Cowell, F.A., Fiorio, C.V.: Inequality decompositions - a reconciliation. J. Econ. Inequal. 9(4), 509-528 (2011)

Cowell, F.A. and E. Flachaire (2002). 'Sensitivity of inequality measures to extreme values'. Discussion Paper DARP 60, STICERD, London School of Economics

Cowell, F.A., Flachaire, E.: Income distribution and inequality measurement: the problem of extreme values. J. Econ. 141, 1044-1072 (2007)

Cowell, F.A., Victoria-Feser, M.P.: Robustness properties of inequality measures: the influence function and the principle of transfers. Economica. 64, 77-101 (1996)

Davies, J.B., Fortin, N.M., Lemieux, T.: Wealth inequality: theory, measurement and decomposition. Canadian Journal of Economics/Revue Canadienne d'Économique. 50, 1224-1261 (2017)

Essama-Nssah, B. and P.J. Lambert (2012). 'Influence Functions for Policy Impact Analysis,' in J.A. Bishop and R. Salas (ed.), Inequality, Mobility and Segregation: Essays in Honor of Jacques Silber, Chapter 6 (Research on Economic Inequality, 20), Emerald, 135-159

Fields, G.S.: Accounting for income inequality and its change: a new method with application to U.S. earnings inequality. In: Polacheck, S.W. (ed.) Research in Labor Economics, 22: Worker Well-Being and Public Policy, pp. 1-38. JAI, Oxford (2003)

Firpo, S., N.M. Fortin, and T. Lemieux (2007). 'Decomposing Wage Distributions Using Recentered Influence Function Regressions'. Unpublished Manuscript, University of British Columbia

Firpo, S., Fortin, N.M., Lemieux, T.: Unconditional quantile regressions. Econometrica. 77, 953-973 (2009)

Foster, J.E.: An axiomatic characterization of the Theil measure of income inequality. J. Econ. Theory. 65, 105$121(1983)$

Foster, J.E., Shneyerov, A.A.: Path independent inequality measures. J. Econ. Theory. 91, 199-222 (2000)

Gradín, C. (2016). 'Why is income inequality so high in Spain?'. In L. Cappellari, S. Polachek, and K. Tatsiramos (Eds.), Inequality around the World, Research on Labor Economics, 44: 109-177

Gradín, C. (2018). 'Explaining cross-state earnings inequality differentials in India: an RIF decomposition approach'. WIDER Working Paper 2018/24. Helsinki: UNU-WIDER

Gradín, C. and F. Tarp (2019). 'Investigating growing inequality in Mozambique', South African Journal of Economics, forthcoming

Hampel, F.R.: The influence curve and its role in robust estimation. J. Am. Stat. Assoc. 60, 383-393 (1974)

Kakwani, N.C.: Measurement of tax progressivity: an international comparison. Econ. J. 87(345), 71-80 (1977)

MEF/DEEF (2016). Pobreza e bem-estar em Moçambique: Quarta avaliação nacional Inquérito ao Orçamento Familiar- 1OF 2014/15. Maputo: Ministerio de Economia e Finanças, Direcção de Estudos Económicos e Financeiros

Monti, A.C.: The study of the Gini concentration ratio by means of the influence function. Statistica. 51(4), 561577 (1991)

Morduch, J., Sicular, T.: Rethinking inequality decomposition, with evidence from rural China. Econ. J. 112, 93106 (2002)

Oaxaca, R.L.: Male-female wage differentials in urban labor markets. Int. Econ. Rev. 14(3), 693-709 (1973)

Rao, V.M.: Two decompositions of concentration ratio. Journal of the Royal Statistical Society. Series A. 132(3), 418-425 (1969)

Rohde, N.: J-divergence measurements of economic inequality. Journal of the Royal Statistical Society A. 179(Part 3), 847-870 (2016)

Sala-i-Martin, X.: The world distribution of income: Falling poverty and ... convergence, period. Q. J. Econ. 121, 351-397 (2006) 
Sastre, M., Trannoy, A.: Shapley inequality decomposition by factor components: some methodological issues. J. Econ. 77(1), 51-89 (2002)

Schechtman, E.: On estimating the asymptotic variance of a function of U statistics. Am. Stat. 45(2), 103-106 (1991)

Shorrocks, A.F.: The class of additively decomposable inequality measures. Econometrica. 48(3), 613-625 (1980)

Shorrocks, A.F.: Inequality decomposition by factor components. Econometrica. 50(1), 193-211 (1982)

Shorrocks, A.F.: Inequality decomposition by population subgroups. Econometrica. 52(6), 1369-1385 (1984)

Shorrocks, A.F.: Aggregation issues in inequality measurement. In: Eichhorn, W. (ed.) Measurement in Economics. Physica Verlag, Heidelberg (1988)

Shorrocks, A.: Decomposition procedures for distributional analysis: a unified framework based on the Shapley value. J. Econ. Inequal. 11(1), 99-126 (2013)

Theil, H.: Economics and Information Theory. North Holland Publishing Company, Amsterdam (1967)

Publisher's Note Springer Nature remains neutral with regard to jurisdictional claims in published maps and institutional affiliations. 